\title{
DNA nanoparticles are safe and nontoxic in non-human primate eyes
}

This article was published in the following Dove Press journal:

International Journal of Nanomedicine

\author{
Ryan A Kelley' \\ Shannon M Conley' \\ Rasha Makkia' \\ Jamie N Watson' \\ Zongchao Han' \\ Mark J Cooper ${ }^{2}$ \\ Muna I Naash ${ }^{3}$ \\ 'Department of Cell Biology, \\ University of Oklahoma Health \\ Sciences Center, Oklahoma City, OK, \\ USA; ${ }^{2}$ Copernicus Therapeutics, Inc., \\ Cleveland, OH, USA; ${ }^{3}$ Department of \\ Biomedical Engineering, University of \\ Houston, Houston, TX, USA
}

Introduction: DNA nanoparticles (NPs) comprising polylysine conjugated to polyethylene glycol efficiently target murine photoreceptors and the retinal pigment epithelium (RPE) and lead to long-term phenotypic improvement in models of retinal degeneration. Advancing this technology requires testing in a large animal model, particularly with regard to safety. So, herein we evaluate NPs in non-human primates (baboon).

Methods and results: NPs with plasmids carrying GFP and a ubiquitous, RPE-specific, or photoreceptor-specific promoter were delivered by either subretinal or intravitreal injection. We detected GFP message and protein in the retina/RPE from eyes dosed with NPs carrying ubiquitously expressed and RPE-specific vectors, and GFP message in eyes injected with NPs carrying photoreceptor-specific vectors. Importantly, we observed NP DNA in the retina/RPE following intravitreal injection, indicating the inner limiting membrane does not prevent NP diffusion into the outer retina. We did not observe any adverse events in any baboon, and there were no NP-associated changes in retinal function. Furthermore, no systemic or local inflammatory reaction to the vectors/injections was observed, and no NP DNA was found outside the eye.

Conclusion: Taken together with the well-established rodent safety and efficacy data, these findings suggest that DNA NPs may be a safe and potentially clinically viable nonviral ocular therapy platform for retinal diseases.

Keywords: DNA nanoparticles, non-human primate, nonviral gene transfer, baboon, gene therapy, safety, ocular gene transfer

\section{Introduction}

The eye offers an excellent target for gene therapy studies due to its easy accessibility, relative immune privilege, and the large number of ocular diseases which are likely to be amenable to genetic treatment. Historically, development of nonviral gene delivery systems has been hampered by limited cell uptake of the vector (resulting in low gene expression levels) or by transient expression, although substantial progress has been made recently in these areas. ${ }^{1,2}$ Our goal over the past several years has been to develop and characterize a nanoparticle (NP)-based approach for effective delivery of genetic cargo to the eye, and more specifically, to the retina and retinal pigment epithelium (RPE), with the eventual goal of identifying a clinically relevant nonviral gene delivery strategy.

Copernicus Therapeutics has developed NPs comprising a single molecule of plasmid DNA compacted with lysine peptides conjugated to polyethylene glycol (CK30PEG), and we have successfully tested these NPs in a variety of mouse models of inherited eye disease. ${ }^{2,3}$ We have shown that they efficiently transfect both photoreceptors ${ }^{3,4}$ and the RPE, ${ }^{2,4,5}$ and can improve the disease phenotype in the $r d s^{+/-}$and rhodopsin-knockout models of retinitis pigmentosa, ${ }^{3,6-8}$ the $\mathrm{Abca}^{-/-}$model of Stargardt's dystrophy, ${ }^{9}$ and the $R p e 65^{-/-}$model of Leber's congenital amaurosis. ${ }^{1,2}$
Correspondence: Muna I Naash Department of Biomedical Engineering, University of Houston, 3517

Cullen Blvd. Room 20I I, Houston,

TX 77204-5060, USA

Tel+I 7|3743 |65I

Emailmnaash@central.uh.edu
International Journal of Nanomedicine 2018:13 |36|-1379

(c) (1) (8) ( 2018 Kelley et al. This work is published and licensed by Dove Medical Press Limited. The full terms of this license are available at https:/Www.dovepress.com/terms.php

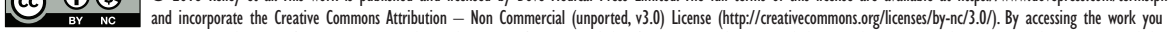
hereby accept the Terms. Non-commercial uses of the work are permitted without any further permission from Dove Medical Press Limited, provided the work is properly attributed. For permision hereby accept the Terms. Non-commercial uses of the work are permitted without any further permission from Dove Mercial use of this work, please see paragraphs 4.2 and 5 of our Terms (https://www.dovepress.com/terms.php).
for commer. 
Importantly, in these cases, we have observed prolonged expression and rescue, often with beneficial effects that persist for the life of the animal. ${ }^{1}$ These NPs have also been successfully used in the lung and brain ${ }^{10-14}$ and result in no toxic effects in the eye $e^{5,6,15}$ even after repeated subretinal injection. ${ }^{5}$ Perhaps most excitingly, these NPs have a large capacity; we have shown that they can successfully incorporate and deliver DNA of up to $14 \mathrm{kbp}$ in photoreceptors (largest size tested) ${ }^{9}$ without significant decrease in transduction efficiency, and others have demonstrated effective transfection in the lung with plasmids of up to $20 \mathrm{kbp}$ (largest size tested). ${ }^{16}$ These results confirm that the CK30PEG NP technology has advanced sufficiently to have the potential to be a successful addition to the available repertoire of clinical ocular gene delivery tools.

Though we have demonstrated proof-of-principle for safety and efficacy many times in rodent models, extensive preclinical evaluation of new strategies in large animal models is key to the development of clinically successful gene-based therapies for patients. Because of differences in the retina among species, non-human primates are widely used as preclinical animal models for ocular disease. The baboon has considerable advantages over other primate species and has a number of characteristics that more closely resemble humans. One of the more obvious is their size; baboons are larger than macaques and most other monkeys, both in terms of body size and eye size, and baboon eyes are much closer to the size of human eyes than those of other primates (Figure S1E; Table S1). In addition, their immune system is similar to that of humans. ${ }^{17,18}$ Although we cannot generate genetic models of disease in baboons (and thus test therapeutic efficacy), these other characteristics make them particularly well suited for assessing a number of critical features of clinically relevant gene therapies. For example, we can assess the route of delivery, tolerance of the NPs, efficacy of gene transfer and gene expression, biodistribution, and immune response. To determine whether NPs are safe and capable of driving gene expression in non-human primates (baboons), herein we evaluated the gene expression and markers of toxicity after intravitreal or subretinal injection of NPs carrying a reporter gene under the control of different promoters. We also demonstrated the reporter gene expression in ocular cells without toxicity after subretinal and/or intravitreal injection of compacted DNA NPs in the baboon retina. We further showed that the inner limiting membrane of the retina did not prevent all DNA NPs from penetrating into the subretinal space as observed by their diffusion into the neural retina and RPE.

\section{Materials and methods}

\section{Animals}

All experiments, procedures, and animal care in this study were approved by the Institutional Animal Care and Use Committees at the University of Oklahoma Health Sciences Center (OUHSC), and all baboon work was done at the OUHSC. Baboons were housed and cared for according to the standards detailed in the Guide for the Care and Use of Laboratory Animals (National Research Council, eighth edition, 2011) and the Association for Assessment and Accreditation of Laboratory Animal Care International. They were fed Harlan primate diet 2055 as well as fresh fruit, vegetables, trail-mix, and dry cereal. Potable water was available ad libitum from automatic waterers. All baboons received daily health checks by the responsible animal care technicians for each area. Considerable effort was placed toward promoting the psychological well-being and providing environmental enhancement for the baboon colonies. Several animals had previously participated in other studies unrelated to the work described here. Detailed information about the animals enrolled in the study is presented in Tables 1 and S2.

\section{Plasmid DNA construction and NP compaction}

We tested three vectors for this study. They were as follows: 1) the pscCBA-GFP vector in which GFP reporter gene expression is directed by the chicken beta-actin promoter ${ }^{19}$ (CBA, known here as CBA-GFP, 5,770 bp ${ }^{19}$ ) originally provided to us by Dr Arun Srivastava, Department of Medicine at the University of Florida; 2) the pEPI-S/MAR vector (backbone originally provided by Dr Isa Stehle/ Hans Lipps, University of Witten/Herdecke) in which GFP expression is driven by the RPE-specific human vitelliform macular dystrophy 2 promoter $^{2}$ (VMD2, -585/+38, known here as VMD2-GFP, ${ }^{20} 6,778$ bp); and 3) the pEPI-S/ MAR vector in which GFP expression is under the control of the photoreceptor-specific promoter rhodopsin kinase (RK, -385/+86, known here as RK-GFP ${ }^{8}$ ). Endotoxin-free $(<5 \mathrm{EU} / \mathrm{mg})$ plasmid DNA was generated by Aldevron, L.L.C. (Fargo, ND, USA) and was unimolecularly compacted into CK30PEG NPs using acetate as the lysine counterion as described previously. ${ }^{13}$ NPs underwent an extensive panel of standardized quality control tests prior to use, and were determined to be rod shaped with a minor diameter of 8-11 nm, a mean length of $\sim 200 \mathrm{~nm}$ (varies depending on plasmid size), and a zeta potential between -3 and $1 \mathrm{mV}$, consistent with what we have used in previous studies. ${ }^{5,9,16,21}$ 
Table I Study enrollment

\begin{tabular}{|c|c|c|c|c|c|c|}
\hline \multirow[t]{2}{*}{ Animal \# } & \multirow[t]{2}{*}{ Treatments } & \multicolumn{2}{|c|}{$\begin{array}{l}\text { Injection } \\
\text { volume }(\mu L)\end{array}$} & \multicolumn{2}{|l|}{ Injection method } & \multirow[t]{2}{*}{$\begin{array}{l}\text { Endpoint } \\
\text { (days) }\end{array}$} \\
\hline & & $\mathbf{R}$ & $\mathbf{L}$ & $\mathbf{R}$ & $\mathbf{L}$ & \\
\hline \multicolumn{7}{|l|}{ Group I } \\
\hline \multicolumn{7}{|l|}{ Controls } \\
\hline 1 & Uninjected & & & & & - \\
\hline 2 & Saline & 100 & 150 & SR, central superior & IV & 15 \\
\hline \multicolumn{7}{|l|}{ CBA-GFP } \\
\hline 3 & NP-CBA-GFP & 100 & 150 & SR, central superior & IV & 15 \\
\hline 4 & Nak-CBA-GFP & 100 & 150 & SR, central superior & IV & 15 \\
\hline \multicolumn{7}{|l|}{ VMD2-GFP } \\
\hline 5 & Nak-VMD2-GFP & 150 & 150 & SR, central superior & SR, central superior & 15 \\
\hline 6 & NP-VMD2-GFP & 150 & 150 & SR, central superior & SR, central superior & 30 \\
\hline $7^{\mathrm{a}}$ & NP/Nak-VMD2-GFP & 150 & 150 & SR, central superior & SR, central superior & 30 \\
\hline 8 & Nak-VMD2-GFP & 150 & 150 & SR, central superior & SR, central superior & 30 \\
\hline \multicolumn{7}{|l|}{ Group 2} \\
\hline \multicolumn{7}{|l|}{ RK-GFP } \\
\hline 9 & NP-RK-GFP & 100 & 100 & One-site SR, temporal inferior & IV & 45 \\
\hline 10 & NP-RK-GFP & 100 & 100 & One-site SR, temporal inferior & IV & 45 \\
\hline 11 & NP-RK-GFP & $50 / 50$ & 100 & $\begin{array}{l}\text { Two-site SR, temporal } \\
\text { inferior, temporal superior }\end{array}$ & IV & 45 \\
\hline 12 & NP-RK-GFP & $50 / 50$ & 100 & $\begin{array}{l}\text { Two-site SR, temporal } \\
\text { inferior, temporal superior }\end{array}$ & IV & 45 \\
\hline 13 & NP-RK-GFP & $50 / 50$ & 50,50 & $\begin{array}{l}\text { Two-site SR, temporal } \\
\text { inferior, temporal superior }\end{array}$ & $\begin{array}{l}\text { Two-site SR, temporal inferior, } \\
\text { temporal superior }\end{array}$ & 45 \\
\hline 14 & NP-RK-GFP & 100 & 100 & One-site SR, temporal inferior & One-site SR, temporal inferior & 45 \\
\hline \multicolumn{7}{|l|}{ Controls } \\
\hline 15 & Saline & $50 / 50$ & 100 & $\begin{array}{l}\text { Two-site SR, temporal } \\
\text { inferior, temporal superior }\end{array}$ & One-site SR, temporal inferior & 45 \\
\hline
\end{tabular}

Notes: A total of 15 baboons were obtained from the breeding colony at the University of Oklahoma Health Sciences Center Baboon Research Resource and subretinally/

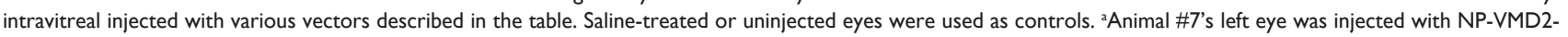
GFP, while the right eye was injected with naked-VMD-GFP.

Abbreviations: IV, intravitreal injection; Nak, naked plasmid; NP, nanoparticle; SR, subretinal injection; UN, uninjected.

NPs of all vectors enrolled in this study were used at a DNA concentration of $4.3 \mu \mathrm{g} / \mu \mathrm{L}$ in saline, which corresponds to $\sim 6.9 \times 10^{11}, 5.88 \times 10^{11}$, and $5.69 \times 10^{11} \mathrm{NP} / \mu \mathrm{L}$ for CBA-GFP, VMD2-GFP, and RK-GFP, respectively. Amounts ranging from 50 to $150 \mu \mathrm{L}$ were injected depending on the study, as described in Table 1.

\section{Subretinal and intravitreal injection in baboons}

A total of 15 baboons were enrolled in this study (Tables 1 and S2). Ketamine (Ketathesia; Butler Animal Health Supply, Dublin, OH, USA) was given intramuscularly at a dose of $\sim 10 \mathrm{mg} / \mathrm{kg}$. Buprenorphine (Buprenex; Reckitt Benckiser Health Care Ltd, Hall, England) was administered subcutaneously at a dose of $0.001 \mathrm{mg} / \mathrm{kg}$, once the baboon was sedated. Anesthesia was maintained with isoflurane administered at $\sim 1.75 \%$ with oxygen through an appropriately sized endotracheal tube. Temperature and oxygen levels were monitored throughout the procedure by the veterinary staff of the
OUHSC Department of Comparative Medicine. Eyes were dilated for 5 minutes using Ak-dilate ${ }^{\mathrm{TM}} 10 \%$ phenylephrine hydrochloride solution (Akorn, 121020; Akorn Pharmaceuticals, Lake Forest, IL, USA). A puncture was created in the sclera of the baboon $2 \mathrm{~mm}$ below the limbus of the eye using a 22-gauge syringe needle under a Zeiss surgical microscope (Carl Zeiss AG, Oberkochen, Germany). Then, a blunt-end microinjection needle ( 25 gauge) was inserted through the puncture to reach the subretinal space or vitreous cavity and $100-150 \mu \mathrm{L}$ (Table 1) of NPs or naked DNA at $4.3 \mu \mathrm{g} / \mu \mathrm{L}$ was delivered. For cases where two subretinal injections were given, $50 \mu \mathrm{L}$ was delivered in each site. The site of injection for each baboon is listed in Table 1 and Figure S1A-D. For CBA-GFP, delivery was subretinal in the right eye and intravitreal in the left eye. For VMD2-GFP, delivery was subretinal in both eyes, due to the RPE-specific nature of the promoter. For RK-GFP, delivery was either done subretinally at two sites, subretinally at one site, or intravitreally, as indicated in Table 1 . Subretinal delivery was confirmed by observation 
of a retinal bleb. Control baboon eyes were left uninjected or were injected with saline using the same conditions described for NPs. During the injection, $100 \mu \mathrm{L}$ of aqueous humor and $\sim 5 \mathrm{~mL}$ of whole blood were collected. Antibiotics (Triple Antibiotic, Walgreens, Oklahoma City, OK, USA) were applied to the eye after injection. Animals were extubated and allowed to recover spontaneously under close observation. They were then placed back in their cages with free access to food and water. Animals were observed daily after the surgery to detect any adverse events up to the study endpoint.

\section{Electroretinography}

For electroretinography (ERG), baboons were anesthetized and monitored as described above for subretinal injections. Following intubation, animals were kept in a dark room with a sleeping eye mask to ensure full dark adaptation. After $30 \mathrm{~min}-$ utes in the dark, eyes were dilated with $1 \%$ cyclopentolate for 5 minutes and covered in 2.5\% methylcellulose (both from Pharmaceutical Systems, Tulsa, OK, USA). The reference electrode was placed under the skin of the forehead, while the ground electrode was placed under the skin at the base of the skull. ERG-jet contact lens electrodes (Micro Components, Grenchen, Switzerland) were gently placed on the cornea and the animal's face was placed inside the ERG ganzfeld. Using the UTAS system (LKC, Gaithersburg, MD, USA) full-field ERG responses were recorded. Scotopic (rod) responses were recorded in response to a single $724 \mathrm{~cd} \mathrm{~s} / \mathrm{m}^{2}$ flash. Animals were then light-adapted for 5 minutes at $29 \mathrm{~cd} / \mathrm{m}^{2}$ and photopic (cone) responses were recorded in response to 25 successive $4.1 \mathrm{~cd} \mathrm{~s} / \mathrm{m}^{2}$ flashes to calculate the photopic A-wave. Photopic responses were then recorded in response to 25 successive flashes at $724 \mathrm{~cd} \mathrm{~s} / \mathrm{m}^{2}$ to calculate the photopic B-wave. Recordings were analyzed and plotted using GraphPad Prism 5 (GraphPad Software, La Jolla, CA, USA). To establish a baseline, ERGs were recorded immediately before the injection of the NPs/vehicle. Follow-up ERGs were done at postinjection (PI)-45 days immediately before euthanasia. For the NP two-site subretinal injection (SR), one-site SR, and IV groups there were four eyes per group. Statistically significant mean changes from baseline to PI-45 were analyzed by one-way Student's $t$-test, testing the hypothesis that mean $\%$ change for each group was statistically different from 0 (ie, no change).

\section{Tissue processing}

Animals were euthanized by intravenous injection with an overdose of sodium pentobarbital $(100 \mathrm{mg} / \mathrm{kg})$ at different time points (Table 1). The following tissues were collected: eye, optic nerve, lateral geniculate nucleus of the brain, and visual cortex. Aqueous humor $(\sim 100 \mu \mathrm{L})$ and serum (extracted from $\sim 5 \mathrm{~mL}$ whole blood) were also collected at the endpoint as well as at the time of injection and were stored at $-80^{\circ} \mathrm{C}$ for subsequent analysis. Eyes injected with CBA-GFP were enucleated and immediately put into cold phosphate buffered saline (PBS). The cornea and lens were then removed and the eye cup was bisected along the nasal-temporal plane. The superior half was fixed with PBS containing 4\% paraformaldehyde for cryosectioning. The inferior half of the eye cup and all other tissues collected were snap-frozen in liquid nitrogen and were pulverized to powder for subsequent analysis. Eyes injected with VMD2-GFP and a subset of eyes injected with RK-GFP were enucleated and eye cups were immediately cut into four quadrants: superior nasal (SN), superior temporal (ST), inferior nasal (IN), and inferior temporal (IT). After removing the retina, the RPE was carefully removed from the eyecup, and both tissues were then snap-frozen in liquid nitrogen and pulverized as indicated above. Remaining eyes injected with RK-GFP were enucleated and immediately placed into cold PBS. The cornea and lens were then removed and the eye cup was placed in PBS containing 8\% paraformaldehyde for 8 hours. The following morning, the eye cups were filled with histogel (Thermo Fisher Scientific, Waltham, MA, USA) and put into cold PBS containing 70\% ethanol. Eyes were then shipped to St Louis University, where they were processed for paraffin sectioning along the inferior-superior plane.

\section{Real-time quantitative reverse transcription polymerase chain reaction}

Real-time quantitative reverse transcription polymerase chain reaction (qRT-PCR) was performed as previously described. ${ }^{9,19}$ Briefly, total RNA was extracted from the pulverized samples using Trizol reagent (Thermo Fisher Scientific) and then $2 \mu \mathrm{g}$ of isolated RNA was treated with RNAse-free DNaseI (Promega Inc., Madison, WI, USA). Reverse transcription (RT) was performed using Superscript III reverse transcriptase (Thermo Fisher Scientific). A no-RT sample was used as a control for any residual compacted DNA or genomic DNA contaminants. Each sample was run in triplicate and the target gene expression levels were calculated relative to the expression of baboon $\beta$-actin, as a delta $\mathrm{CT}$ according to the following formula: expression $=2^{-(\mathrm{GFP} C \mathrm{CT}-\text { actin } \mathrm{CT})}$. We did not observe any GFP expression in the uninjected, salineinjected, or no-RT controls. The primers used were 1) $\beta$-actin, F-TGTTACCAACTGGGACGACA and R-GGGGTGTTG AAGGTCTCAAA, and 2) GFP, F-AGGAGCGCACCAT CTTCTT and R-GATGTTGTGGCGGATCTTG. 


\section{Quantitative polymerase chain reaction}

Quantitative PCR (qPCR) was performed using the same protocol described for qRT-PCR, with the exception that total DNA was used as the template instead of RNA. DNA was extracted from pulverized retina or RPE using a DNA lysis buffer containing $100 \mathrm{mM}$ Tris, $100 \mathrm{mM} \mathrm{NaCl}, 10 \mathrm{mM}$ EDTA, and $0.5 \%$ sodium dodecyl sulfate in water. Samples were incubated in $500 \mu \mathrm{L}$ DNA lysis buffer in a $50^{\circ} \mathrm{C}$ water bath for 4 hours. Two hundred and fifty microliters of $5 \mathrm{M}$ $\mathrm{NaCl}$ was added to each tube and shaken by hand $\sim 25$ times. The samples were then incubated at $4^{\circ} \mathrm{C}$ for 10 minutes and centrifuged at $4,000 \times g$ at $4^{\circ} \mathrm{C}$ for 10 minutes. The supernatant was moved to a fresh tube containing $650 \mu \mathrm{L}$ isopropanol. Samples were incubated for 15 minutes at room temperature. The samples were then centrifuged at $14,000 \times g$ for 10 minutes at room temperature. The supernatant was removed and the pellets (containing the DNA) were allowed to air dry for 5 minutes at room temperature. Samples were resuspended in water and diluted to a final concentration of $40 \mu \mathrm{g} / \mu \mathrm{L}$, and used as template for qPCR reactions (80 $\mathrm{ng}$ per well). Positive controls included $80 \mathrm{ng}$ of RPE or optic nerve DNA from the saline-injected animal spiked with $8 \mathrm{ng}$ of RK-GFP plasmid. The primers used were 1) $\beta$-actin, F-TGTTACCAACTGGGACGACA and R-GGGGTGTTG AAGGTCTCAAA, and 2) GFP, F-AGGAGCGCACCAT CTTCTT and R-GATGTTGTGGCGGATCTTG.

\section{Western blot}

Western blot was performed as described previously. ${ }^{9,19}$ Briefly, protein extracts were prepared from pulverized powder of the retina plus pigment epithelium/choroid/sclera (PECS) by homogenization in lysis buffer $(25 \mathrm{mM}$ Tris $\mathrm{pH} 7.5,150 \mathrm{mM} \mathrm{NaCl}, 1 \% \mathrm{NP}-40,1 \%$ sodium deoxycholate, $0.1 \%$ sodium dodecyl sulfate, $1 \mathrm{mM}$ EDTA, and $1 \mu \mathrm{g} / \mathrm{mL}$ leupeptin). Protein concentration was determined using the BioRad protein assay kit (Bradford assay; Bio-Rad Laboratories Inc., Hercules, CA, USA). Primary antibodies were anti-GFP (1:1,000, A11122, Thermo Fisher Scientific) or actin-horse radish peroxidase (1:25,000; Sigma-Aldrich, St Louis, MO, USA). Secondary antibodies were horse radish peroxidaseconjugated anti-rabbit or anti-mouse IgG (1:25,000; KPL antibodies from Seracare Life Sciences Inc, Milford, MA, USA). Retinal lysates from GPI-GFP transgenic mice ${ }^{22}$ were used as positive controls for immunoblotting.

\section{Cytokine protein assay}

Aqueous humor and serum were evaluated for cytokine protein levels as described previously ${ }^{5}$ using the Bio-plex assay. Briefly, the samples were assayed for interleukin (IL)-6, IL-1 $\beta$, tumor necrosis factor (TNF)- $\alpha$, and interferon (IFN)- $\gamma$ using a non-human primate cytokine premixed kit as per the manufacturer's instructions (Cat. MPXPRCYTO40K; EMD Millipore, Billerica, MA, USA). Controls included eight standards run in duplicate, two positive controls (serum from a dengue virus-infected baboon and from an influenza virus-infected baboon), and two blank wells. All samples were run in triplicate.

\section{Histology and immunohistochemistry}

Tissue fixation and sectioning were performed as described previously. ${ }^{5,19}$ Paraffin sections were collected along the vertical meridian. To assess GFP expression, tissues were stained using the $\mathrm{ABC}$ elite enzyme-based immunohistochemistry kit as per the manufacturer's instructions (PK-6200; Vector Laboratories, Burlingame, CA, USA) using the GFP antibody described in the Western blot section. Positive control sections were incubated with RPE65 antibody (Cat ab13826; Abcam, Cambridge, MA, USA). GFP antibody was also used to stain sections obtained from knockin mice that express GFP under the control of a photoreceptor-specific promoter (retbindin), as a positive control for GFP labeling. Briefly, superior central retinal sections were air dried, fixed with methanol, and blocked using $0.3 \%$ normal horse serum in PBS. Slides were incubated in primary antiserum diluted in buffer and washed for 5 minutes. Primary antibody was applied to the sections for 1 hour at room temperature. Sections were then incubated with biotinylated anti-rabbit secondary antibody, followed by washing. Sections were incubated with Vectastain ${ }^{\circledR}$ Elite $\mathrm{ABC}$ Reagent and then with Vector VIP (SK-4600), a peroxidase substrate which produces a purple stain corresponding to the bound primary antibody. Vector methyl green (H-3402) was used for counterstaining the nuclei. Finally, sections were dehydrated using ethanol and mounted in permount solution. Enzyme-based staining was used rather than fluorescence due to the high autofluorescence and large quantity of dark pigment in the baboon eyes/RPE. Images were captured on a Nikon E800 microscope coupled to a MicroMax-5MHz-1300Y cooled charge-coupled device camera (Princeton Instruments, Acton, MA, USA) and the MetaVue software (Molecular Devices, Sunnyvale, CA, USA).

\section{Ethics approval}

All animal procedures were approved by the Institutional Animal Care and Use Committees at the OUHSC and all baboon work was done at the OUHSC. Baboons were 
housed and cared for according to the standards detailed in the Guide for the Care and Use of Laboratory Animals (National Research Council, eighth edition, 2011) and the Association for Assessment and Accreditation of Laboratory Animal Care International.

\section{Results}

\section{Clinical evaluation}

As described in Tables 1 and S2, a total of 15 baboons were enrolled in one of two overall groups with animals ranging in age from 2 to 22 years and a median age of 15 years. Both male and female animals were enrolled. In the first group, animals were either controls (uninjected/saline), subretinally or intravitreally injected with naked (ie, uncompacted) or NP-CBA-GFP, or subretinally injected with naked or NP-VMD2-GFP. In the second group, animals were either controls (saline) or injected with NP-RK-GFP. In this group, one of our goals was to evaluate the effects of a single bolus injection compared to smaller injection volumes at multiple sites, so animals were either intravitreally injected, subretinally injected at a single site, or subretinally injected at two sites. Follow-up was at PI-15, PI-30, or PI-45 days (Table 1); animals were euthanized and tissues were harvested, including the eye, brain, and blood. All baboon eyes were normal at the time of treatment. Following injection, the cornea and the lens remained clear. There was no evidence of ocular pathology, except some common effects after the injection such as a slight conjunctival reaction, which occurred equally in NP and vehicle-treated animals and disappeared within 3-5 days after injection. Antibiotic was applied to the injected eyes after the surgery. After recovery from the injection procedure, no baboons were reported to have any complications with everyday behaviors that could have been attributed to vision loss. No abnormalities were noted in any treated animals. Our goals in this study were 1) to determine whether compacted DNA NPs could drive gene expression in the non-human primate eye; 2) to determine whether the injection route affected gene expression/safety; and 3) to determine whether there were overt signs of toxicity in response to the NPs. As a result, our outcomes are divided into those measuring gene expression and those associated with safety and response to the treatment.

\section{NPs drive gene expression in the baboon eye}

We first evaluated gene expression after delivery of NP and naked-CBA-GFP in the baboon eye. This plasmid has the pSC vector backbone used to generate generate adenoassociated virus (AAV), and we have previously shown that it generates robust gene expression in the rodent eye. ${ }^{19}$ In this cohort, the right eye was subretinally injected while the left eye was intravitreally injected. Throughout the manuscript, we present data from individual eyes as well as mean values, since the cost of animals necessarily restricts the sample size. To aid interpretation, results from intravitreally injected animals are always presented as squares, single site subretinal injections as circles, and dual site subretinal injections as upright triangles (where relevant).

Three animals were used for this initial evaluation of CBA-GFP: one for naked (uncompacted) CBA-GFP, one for NP-CBA-GFP, and one saline control, with one eye subretinally injected and one eye intravitreally injected (Table 1). Tissues were collected at PI-15 days for analysis by qRT-PCR and Western blot (refer to Figure S1 for details on collection). Previously, we had observed gene expression in the cornea and lens after delivery of NPs in the murine eye; ${ }^{4}$ however, neither intravitreal nor subretinal injection led to detectable GFP message in the baboon anterior segment tissues (Figure 1A, left). In contrast, we detected GFP message in the posterior segment, specifically in samples consisting of the retina plus PECS after both subretinal and intravitreal injections of NPs, with higher expression occurring after subretinal delivery (Figure 1A, right). NakedCBA-GFP was very inefficient; only a very low level of GFP message (slightly above the background) was detected in the retina plus PECS sample (Figure 1A, right). These results were recapitulated on Western blots of retina plus PECS samples; GFP protein was detected from NP-injected, but not naked DNA-injected eyes, regardless of the delivery route (Figure 1B). Lysates from GPI-GFP transgenic mice were used as a positive control for GFP protein. No expression from NPs or naked DNA was detected in the optic nerve or in any sample from the saline (vehicle)-injected eyes (Figure 1A). These encouraging results suggest that subretinal and intravitreal delivery of NP-CBA-GFP can transduce the posterior segment without generating expression in the anterior segment or optic nerve.

We have previously observed excellent expression and phenotypic correction of RPE-based diseases after delivery of NPs carrying vectors in which gene expression was driven by the RPE-specific VMD2 promoter. ${ }^{1,2}$ So, we next asked whether VMD2-GFP could transduce the baboon RPE. For these studies, the VMD2-GFP expression cassette was cloned into the pEPI vector backbone which contains a scaffold/matrix attachment region. This region is thought to promote improved gene expression/longevity, and we have previously used this vector for delivery of genes in the rodent eye with great success. ${ }^{1,2}$ As these experiments were 

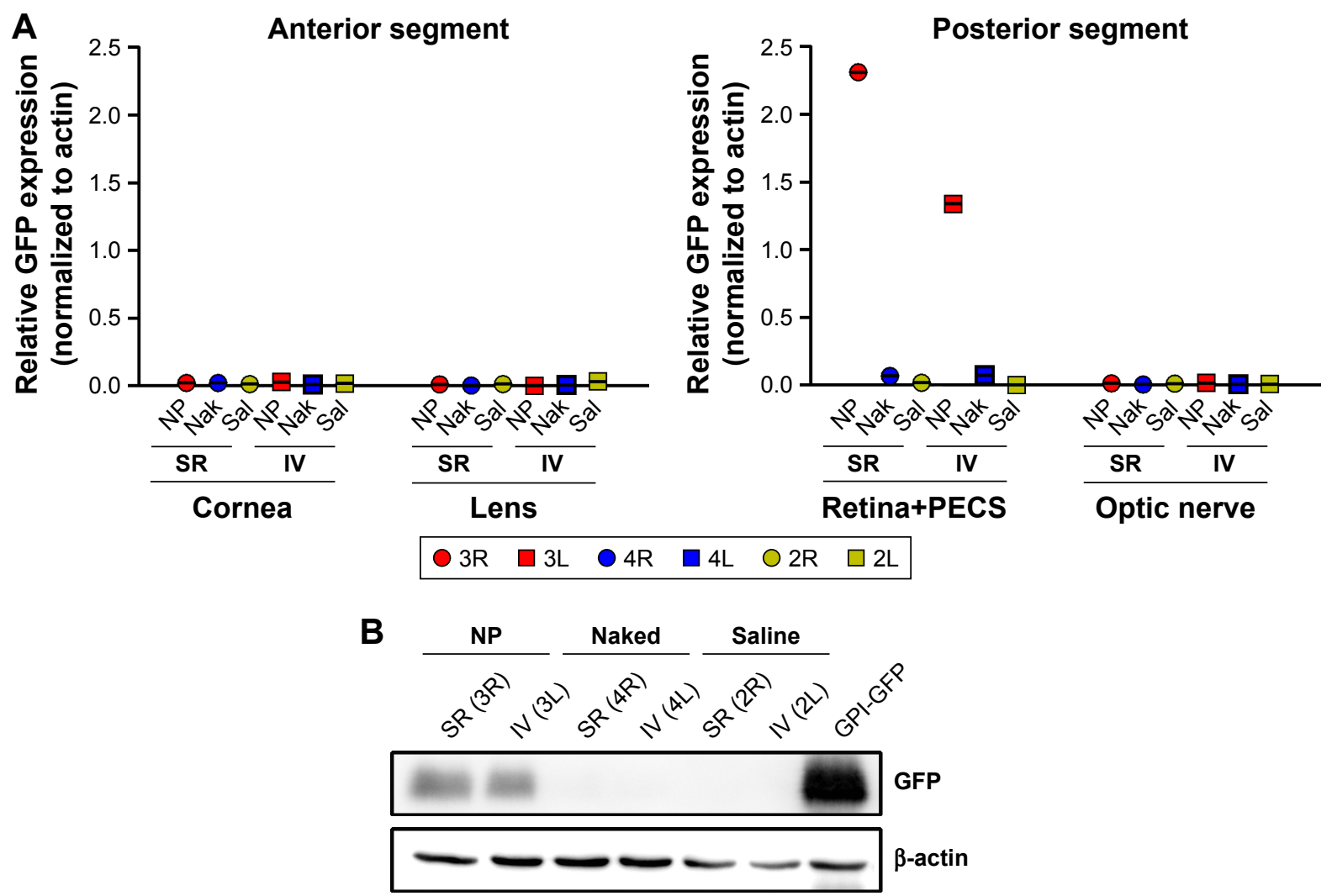

Figure I GFP expression after a single subretinal or intravitreal injection of NP-CBA-GFP in baboon eyes.

Notes: Tissues were harvested from animals subretinally or intravitreally injected with either naked CBA-GFP, NP CBA-GFP, or vehicle (saline). (A) Expression of GFP message by qRT-PCR in the anterior segment (cornea and lens, left) and posterior segment (retina+PECS and optic nerve, right). GFP values were normalized to actin. Each eye is shown as an individual symbol with NPs in red, naked DNA in blue, saline in yellow, and subretinal/intravitreal in circles/squares, respectively. Legend indicates animal \#/eye. (B) Western blot analysis for GFP protein (or actin as a loading control) in lysates ( $50 \mu \mathrm{g} / \mathrm{lane}$ ) from retina+PECS. Retinal lysates from GPI-GFP transgenic mice were used as a positive control.

Abbreviations: IV, intravitreal injection; Nak, naked plasmid; NP, nanoparticle; PECS, pigment epithelium, choroid, and sclera; qRT-PCR, quantitative reverse transcription polymerase chain reaction; Sal, saline; SR, subretinal injection.

specifically targeted to the RPE, all eyes were subretinally injected with either naked or NP-VMD2-GFP. Four animals were enrolled in this study (Table 1). The first animal enrolled (animal \#5) was injected with naked VMD2-GFP, and qRTPCR for GFP message was performed on RPE and retina samples isolated at PI-15 days as well as from uninjected and saline-injected controls. GFP message was detected in the RPE from both eyes and in one retina sample from animal $\# 5$, but not in negative controls (Figure 2A). VMD2 is a wellcharacterized RPE-specific promoter. ${ }^{1,2}$ For example, we have found that NPs carrying VMD2-GFP vectors are expressed only in the RPE, not in the associated neural retina. ${ }^{20}$ Thus, the
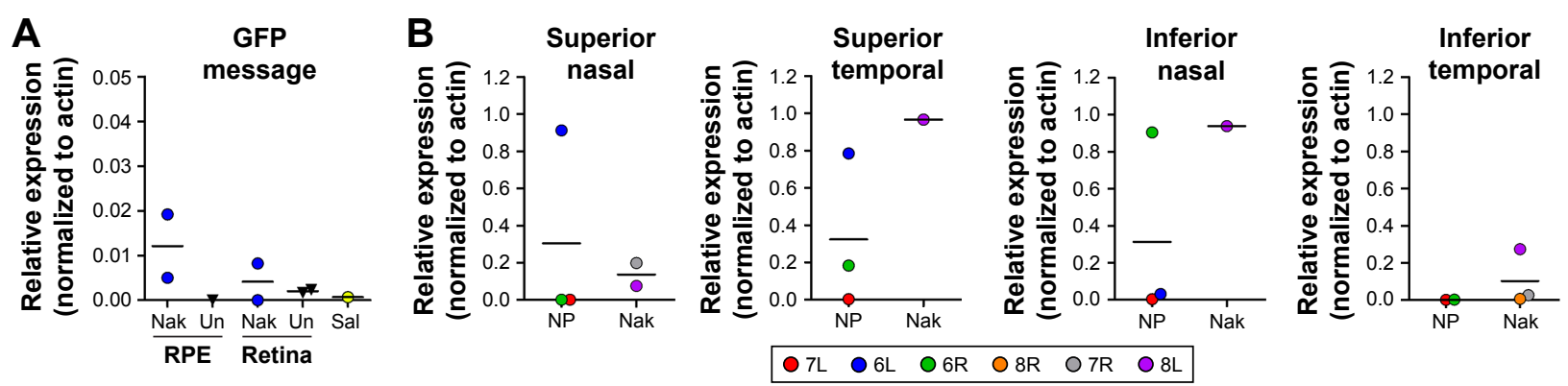

Figure 2 GFP expression after a single subretinal injection of VMD2-GFP-S/MAR in baboon eyes.

Notes: Tissues were harvested at the times indicated in Table I from animals subretinally injected with naked VMD2-GFP or NP VMD2-GFP (or vehicle). (A) Expression of GFP message was assessed by qRT-PCR in the RPE and retina from animal \#5 (naked DNA, blue circles), animal \#I (uninjected, black triangles), and animal \#2 (saline, yellow circles). (B) In subsequent animals, QRT-PCR for GFP was performed on RPE tissue isolated from various quadrants after a single subretinal injection. GFP values were normalized to $\beta$-actin. Each eye is shown as an individual symbol. Symbols are consistently colored from quadrant to quadrant; legend indicates animal \#/eye. Black lines indicate mean. Abbreviations: Nak, naked plasmid; NP, nanoparticle; qRT-PCR, quantitative reverse transcription polymerase chain reaction; RPE, retinal pigment epithelium; Sal, saline. 
retina expression we observed may be due to contamination from some RPE tissue. These results confirmed that VMD2GFP was capable of driving gene expression in the baboon and encouraged us to enroll additional animals. To determine whether the expression persisted past 2 weeks, the endpoint for the remaining three animals was PI-30 days. In addition, for the remaining animals, RPE tissue was harvested from all four quadrants of the eye, as described in the "Materials and methods" section, to assess the levels of expression at several different locations (Figure 2B, the color of the symbols corresponds with an individual eye). Expression was variable from quadrant to quadrant and from animal to animal, but high expression was frequently detected in the superior half of the eye, consistent with the site of injection, although some expression was detected in all quadrants. The lowest expression was observed in the IT quadrant (Figure 2B, right). Two out of three NP-injected eyes (\#6L and \#6R) exhibited robust expression in at least two quadrants, while one NP-injected eye did not exhibit any detectable expression (\#7L), as shown in Figure 2B. Importantly, as we have previously observed with this vector, ${ }^{1,2}$ expression was observed with naked-VMD2-GFP as well as NP-VMD2-GFP; eye \#8L exhibited expression in all four quadrants (Figure 2B), consistent with the results we observed in animal \#5 (Figure 2A), while other eyes had little expression. To assess the distribution and tissue specificity of GFP protein, we collected small pieces of retina/PECS from two animals (\#7 and \#8) and performed immunohistochemistry with antibodies against GFP or RPE65 (as a positive control). GFP expression (purple) was detected specifically in the RPE (arrowheads) after injection of naked-VMD2GFP (Figure 3A, 60×) or NP-VMD2-GFP (Figure 3B, 60×) in the examined eyes. GFP labeling in the RPE exhibited the same pattern as RPE65 labeling (Figure S2, 20×; Figure 3C, $60 \times$ ). Labeling with secondary antibodies alone (Figure 3D, $20 \times$ ) is shown as a negative control. Though GFP expression was widespread in the retinal sections and was not limited to the site of injection, there were areas of the RPE that did not show GFP expression. Figure 3E shows images at the same magnification $(20 \times)$ from a region that did not express GFP (Figure 3E, left) compared to a region that did express GFP (Figure 3E, right, arrowheads). These data indicate that VMD2-GFP is well expressed in the RPE of baboons either 15 or 30 days after subretinal delivery of NPs or naked DNA.

Our second group of baboons was dosed with NPs carrying the photoreceptor-specific expression cassette RK-GFP (rhodopsin kinase promoter) in the pEPI backbone. Seven animals were enrolled in this experimental group (Tables 1 and S2), and animals received an intravitreal injection $(100 \mu \mathrm{L})$, a subretinal injection at a single site $(100 \mu \mathrm{L})$,
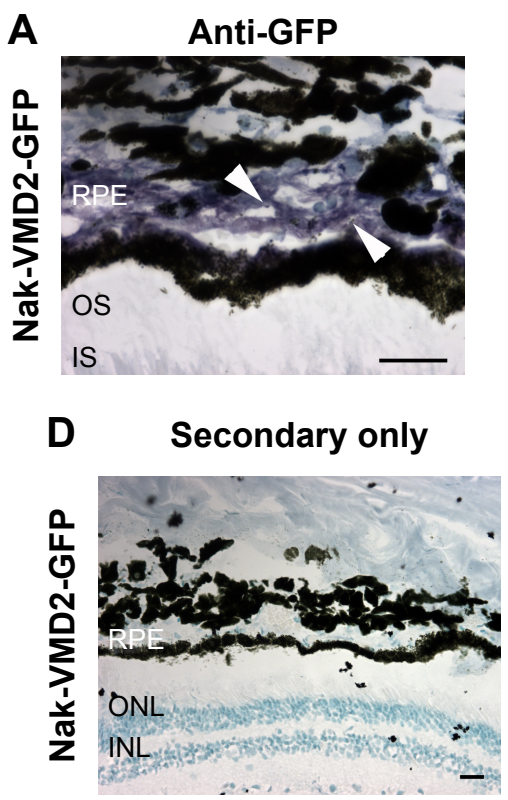
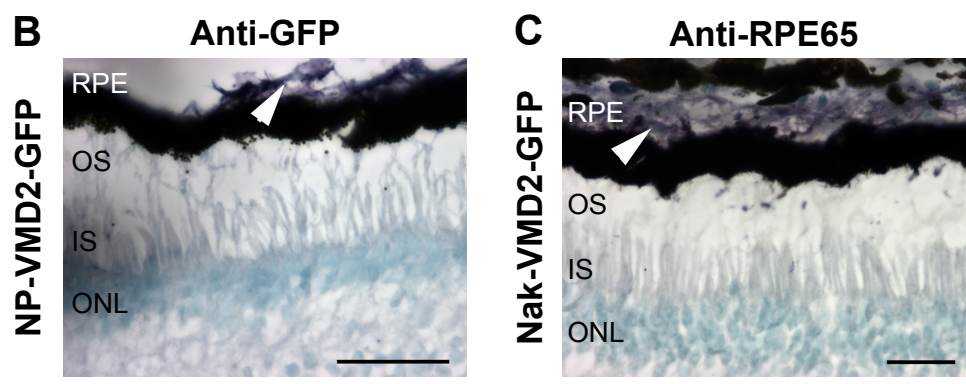

E

Anti-GFP
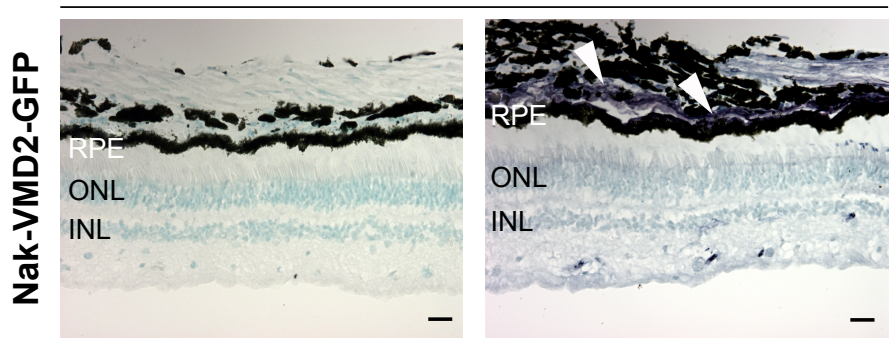

Figure 3 GFP is expressed in the RPE after delivery of VMD2-GFP-S/MAR.

Notes: (A-E) Immunohistochemistry was performed on retinal sections with antibodies against GFP (A, B, E), RPE65 as a control for RPE labeling (C), or with secondary antibodies alone (D). The purple coloring indicates GFP/RPE65 antibody labeling with nuclei counterstained with methyl green (teal). White arrowheads indicate expression in the RPE. (E) Images at $20 \times$ from a region not expressing GFP (left) and a region expressing GFP (right). Animal/eye numbers are as follows: (A, C, D, E) 7R, (B) 7L. Scale bar: $25 \mu \mathrm{m}$.

Abbreviations: INL, inner nuclear layer; IS, inner segment; Nak, naked plasmid; NP, nanoparticle; ONL, outer nuclear layer; OS, outer segment; RPE, retinal pigment epithelium; Sal, saline; UN, uninjected. 
or subretinal injections at two different sites (50 $\mu \mathrm{L}$ each). Because we have previously found that naked DNA does not transfect photoreceptors well, ${ }^{4}$ only NPs or saline was injected in this study. Injected eyes were either enucleated and fixed for immunohistochemistry or retinas were collected and divided into four quadrants for molecular analysis. Brain tissues and optic nerves were also collected from all animals. Modest GFP message levels were detected in multiple samples relative to saline controls (which had no expression, Figure 4A), and as with VMD2-GFP-injected eyes, the expression levels varied from quadrant to quadrant and from animal to animal. In the two-site injection group, one out of three eyes exhibited no expression in any quadrant (Figure 4A, \#13L), while two out of three eyes exhibited low levels of expression in two quadrants (Figure 4A, \#11R and \#13R). The one eye from the one-site subretinal group for which tissue was collected for qRT-PCR exhibited robust expression in the quadrant containing the site of injection (Figure 4A, right \#9R), with low expression in the remaining quadrants, suggesting that injecting multiple sites improved distribution of expression. Neither of the two intravitreally injected eyes exhibited robust GFP message, although one eye showed a low level of expression in the ST quadrant (Figure 4A, \#11L). The eyes not collected for qRT-PCR were processed for serial sectioning to assess GFP protein expression across the retina. However, no GFP protein was detected in any retinal sections from two-site subretinal, one-site subretinal, or intravitreal injected baboons either near the site of injection or in other regions of the retina (an example is shown in Figure S3).

Given the low levels of GFP message detected and the lack of GFP protein detected, we hypothesized that NP-RKGFP could be phagocytosed by the RPE before it had a chance to be taken up and expressed in photoreceptors. Therefore, we performed qPCR for NP-RK-GFP vector DNA on samples isolated from pulverized retina (Figure 4B, filled symbols) and RPE tissue (Figure 4B, open symbols). In two out of three eyes in the two-site subretinal group, no NP-RK-GFP DNA was detected in the retina (Figure 4B, \#13L, \#13R), while in the third eye (Figure 4B, \#11R), retinal NP-RK-GFP DNA was detected only in the quadrants injected (ST and IT). The one-site subretinal eye which exhibited robust GFP transcript levels in the IT quadrant of the retina (site of injection,
A

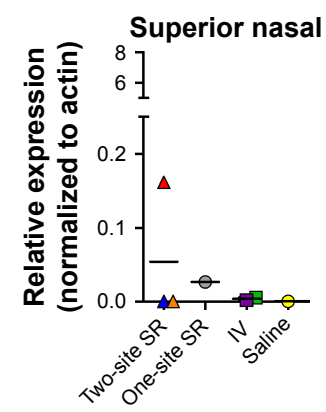

eGFP message, retina

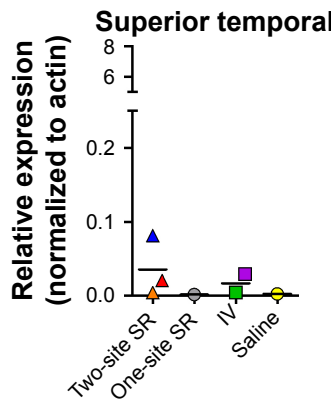

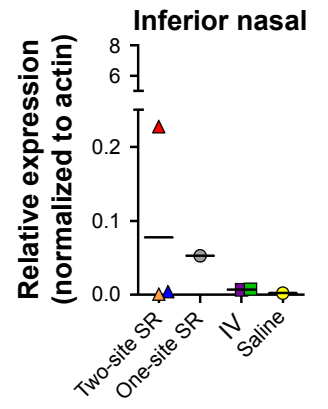

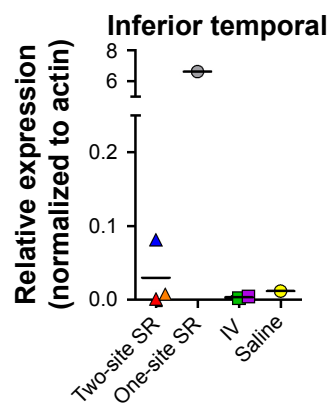

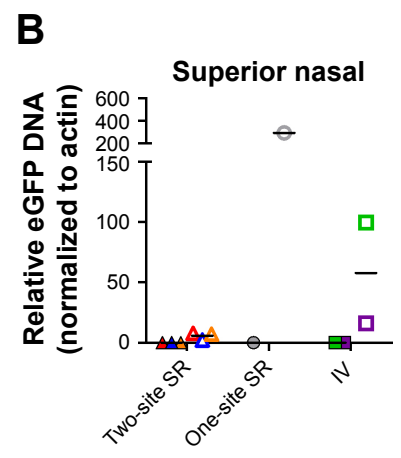

eGFP DNA, retina (closed symbols) and RPE (open symbols)
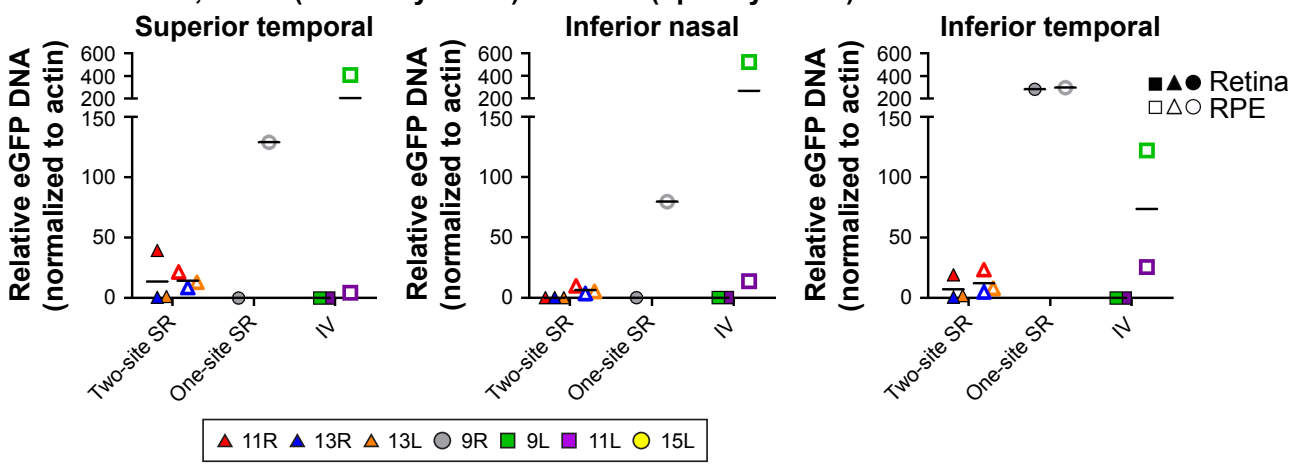

Figure 4 RK-GFP DNA was detected in the retina and RPE.

Notes: Retinas and RPE were harvested from animals subretinally (two-site or one-site) or intravitreally injected with NP RK-GFP or saline. (A) Expression of GFP message as measured by qRT-PCR in the four quadrants of eyes receiving two-site subretinal injections (triangle), one-site subretinal injections (circle), or intravitreal injections (square). Colors correspond to individual eyes and are the same in (B). Black lines indicate mean. (B) Relative levels of RK-GFP DNA were measured in injected eyes by qPCR in the retina (closed symbols) and RPE (open symbols). Black bar indicates mean. Legend indicates animal \#/eye.

Abbreviations: IV, intravitreal injection; SR, subretinal injection; NP, nanoparticle; qPCR, quantitative polymerase chain reaction; qRT-PCR, quantitative reverse transcription polymerase chain reaction; RPE, retinal pigment epithelium. 
Figure 4A, \#9R) also exhibited retinal NP-RK-GFP DNA in the IT quadrant (Figure 4B, \#9R), but not in other quadrants. In contrast, the one-site subretinal injected eye demonstrated DNA in the RPE from all four quadrants. No NP-RK-GFP DNA was detected in the retina in intravitreally injected eyes. However, NP-RK-GFP DNA was found in the RPE in all four quadrants following intravitreal dosing, indicating that these NPs could diffuse through the retina and were not restricted by the inner limiting membrane.

\section{NPs are safe and well-tolerated in the baboon eye after subretinal and intravitreal injection}

In addition to determining whether compacted DNA NPs could drive gene expression in the baboon eye, our second goal was to determine whether there were any adverse events in response to the NP treatments. One of the easiest ways to assess whether there is overt retinal toxicity in response to the NPs was to determine by ERG whether there was any decrease in retinal function from baseline to the study endpoint. Therefore, we conducted full-field scotopic and photopic ERGs on all group 2 animals immediately prior to the injections and at the study endpoint (PI-45 days). Figure 5A and $\mathrm{C}$ show representative scotopic and photopic wave forms preinjection and PI, respectively. Arrows identify the scotopic A-wave (a measure of photoreceptor function), while arrowheads identify the scotopic B-wave (a measure of second-order neuron function). Figure 5B and D plot mean change from baseline to PI in maximum scotopic and photopic A- and B-wave amplitudes. Overall, single-site subretinal injections were well tolerated; there was no significant difference (ie, posttreatment vs pretreatment) in mean scotopic or photopic retinal function in the single-site subretinal injection group. Three out of four eyes (\#9R, \#14L, \#14R) had no change or slightly improved scotopic A-wave (Figure 5B, left), photopic A-wave, and photopic B-wave (Figure 5D) responses after injection, and two out of four eyes had no change or improved scotopic B-wave injections (Figure 5B, right). Intravitreal injections were also fairly well tolerated; there was no significant difference (ie, posttreatment vs pretreatment) in mean scotopic or photopic retinal function in the intravitreal injection group. Two out of four eyes had no change or slight improvement in scotopic A- and B-wave amplitudes (Figure 5B), while three out of four eyes had no change or improvement in photopic A- and B-wave amplitudes (Figure 5D, \#9L, \#11L, \#12L). Two-site subretinal injections were the least well tolerated; there was a statistically significant decrease (ie, posttreatment vs pretreatment) in mean scotopic A- and B-waves in this group, although photopic responses were not significantly altered. Three out of four eyes showed slight decreases in scotopic A- and B-waves, while one out of four eyes had more severely decreased scotopic A- (Figure 5B, left, \#11R) and B- (Figure 5B, right, \#13R) waves. Similarly, three out of four eyes showed slight decreases in photopic A- and B-waves, while only one out of four eyes showed no change in photopic responses (Figure 5D). This decrease in response is likely due to the subretinal injection procedure rather than the NPs, since the two-site saline-injected eye also exhibited a large decrease in photopic A-wave responses (though not scotopic responses), and additional saline-injected eyes would help clarify this issue. Interestingly, the four eyes that exhibited the lowest scotopic responses across all injection types (Figure 5B, left) came from the same two animals (\#10L/R and \#11L/R), suggesting that those two individuals may have been more susceptible to any kind of injection procedure. Similarly, other animals exhibited uniformly good responses regardless of injection type, for example, animal \#9 (one eye intravitreal, one eye one-site subretinal). However, these animals did not exhibit any distinguishing characteristics (age, study history, and so on) that could explain this, so it may simply be due to individual variability. Although saline injections have previously been shown to mediate some improvements in degenerative models, possibly due to induction of protective responses, the improvements we see here are very small and likely within test-retest variability and regular diurnal/day-to-day variability in responses. However, a lack of significant decrease in ERG function in many treated eyes is a good sign that the NPs and injection procedures do not induce significant toxic effects or degeneration.

We next determined whether the injection of the NPs or naked DNA caused local induction of inflammatory mediators, by measuring the protein expression of proinflammatory cytokines. We assessed IL-6, IFN- $\gamma$, IL- $1 \beta$, and TNF- $\alpha$ in aqueous humor samples (Figure 6A and B, each symbol is a single sample; however, the color scheme has been simplified from prior figures for ease of interpretation) collected from animals in group 1 immediately before injection or at the study endpoint (PI-15 or PI-30 days) using a Bio-Plex protein assay. Serum from an animal infected with dengue fever virus as part of a separate study was used as a positive control for these inflammatory mediators. None of these cytokines were elevated in the aqueous humor after treatment (open symbols) compared to preinjection (closed symbols) or aqueous humor from an uninjected animal, after either 

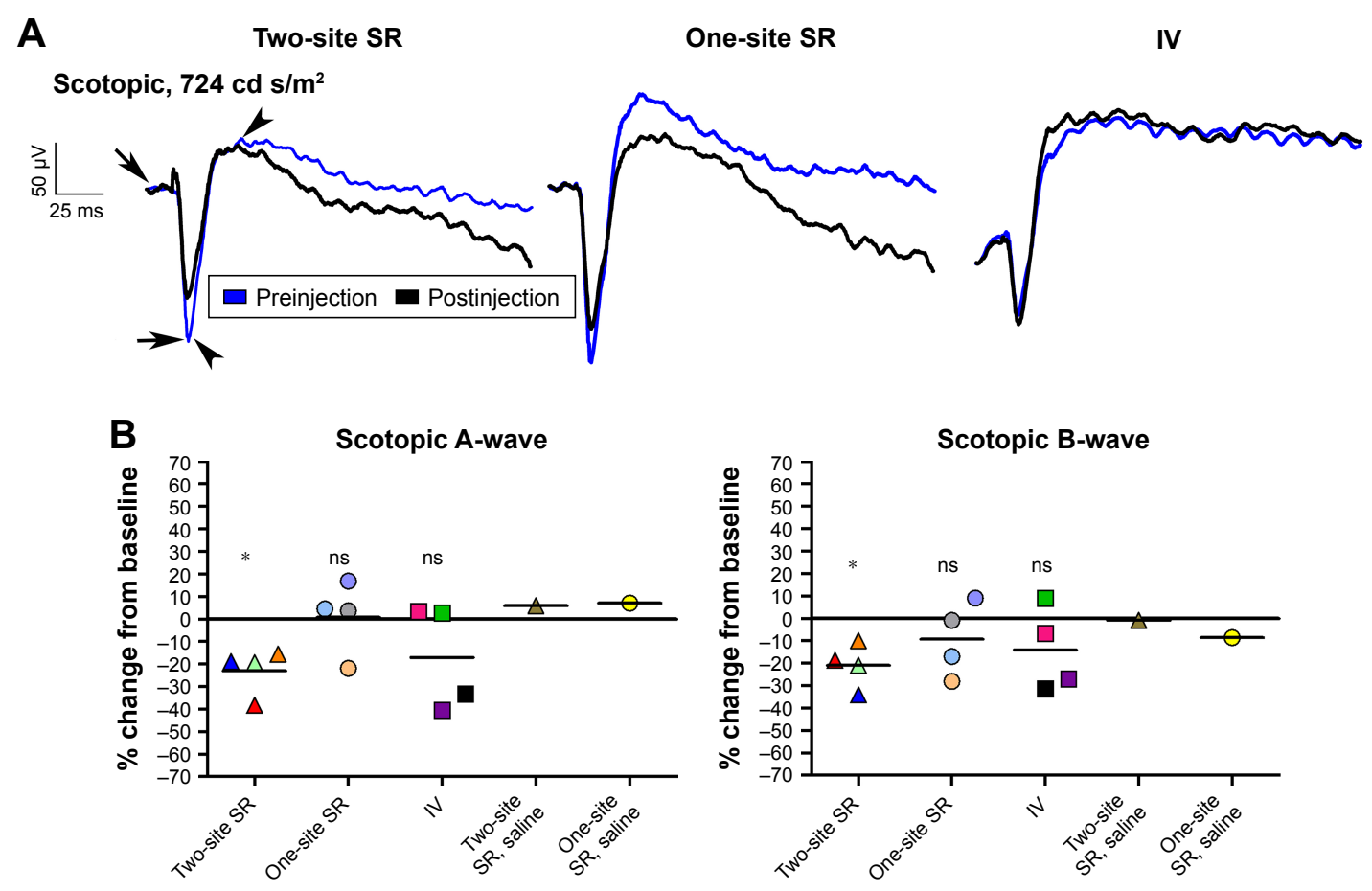

C Two-site SR

One-site SR

IV
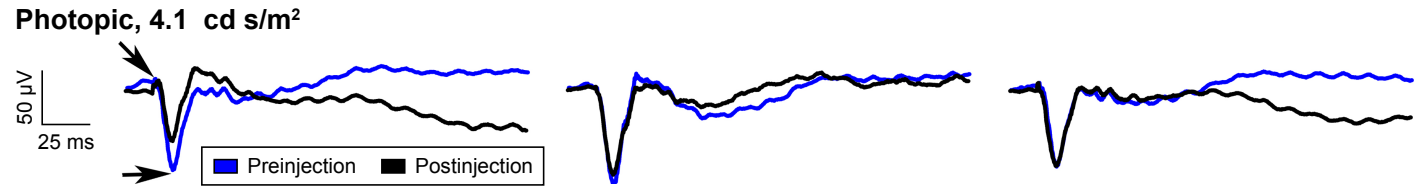

Photopic, $724 \mathrm{~cd} \mathrm{~s} / \mathrm{m}^{2}$
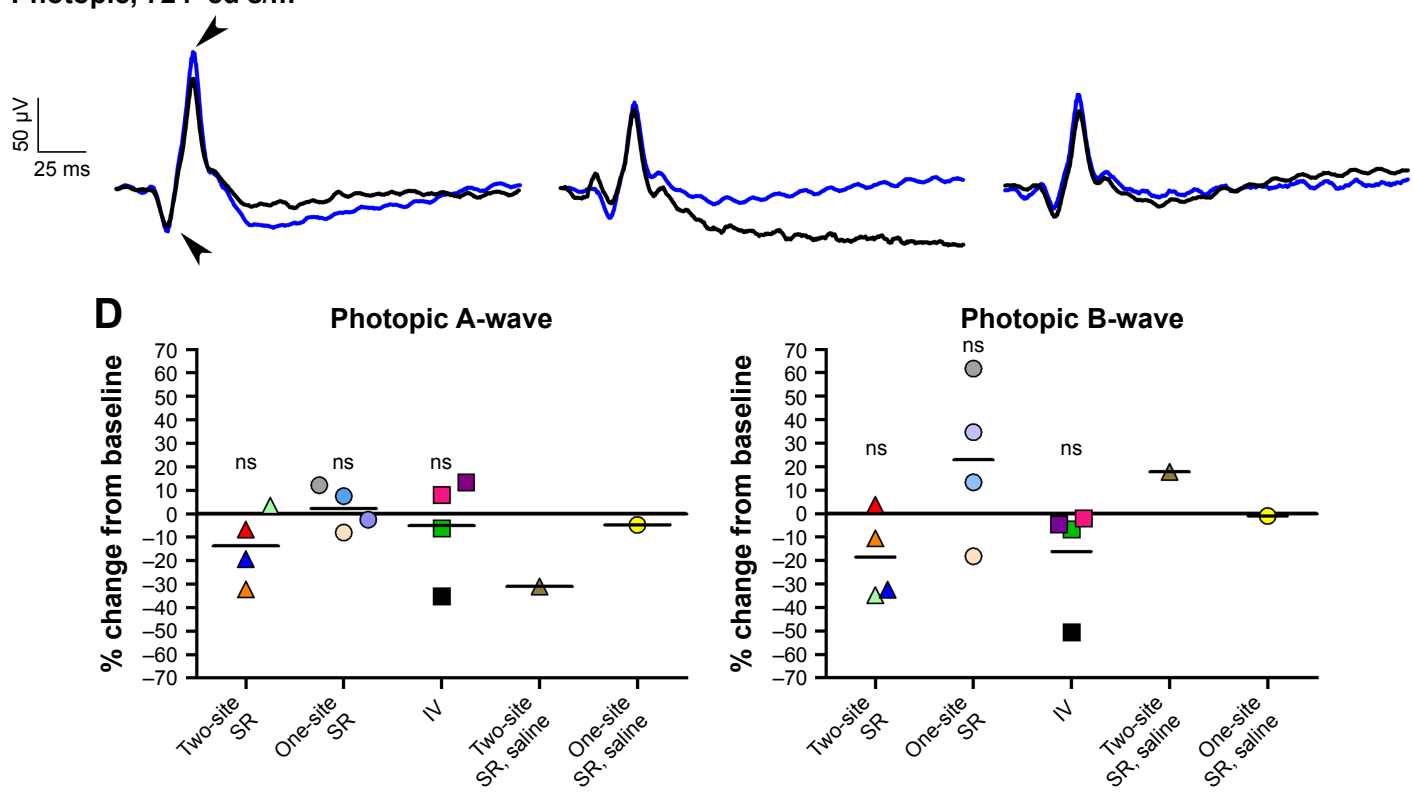

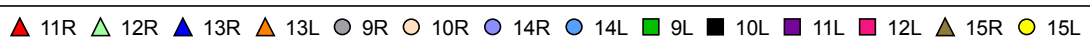

Figure 5 Intraocular delivery of nanoparticle DNA caused a modest decrease in retinal function.

Notes: Animals from group 2 (Tables I and S2) underwent electroretinography immediately before injection and 45 days after injection. (A, C) Shown are representative (A) scotopic and (C) photopic wave forms before (blue) and after (black) injection. Arrows indicate the places where the A-wave was measured, while the arrowheads indicate the places where the B-wave was measured. (B, D) Graphical representation of the percent change in maximum (B) scotopic and (D) photopic amplitudes. Black lines indicate mean. Colors correspond to individual eyes; legend lists animal \#/eye. $* P<0.05$, ns $=$ nonsignificant in one-way Student's $t$-test testing the hypothesis that the mean \% difference is different from 0 (ie, that there is significant change from baseline).

Abbreviations: IV, intravitreal injection; SR, subretinal injection. 

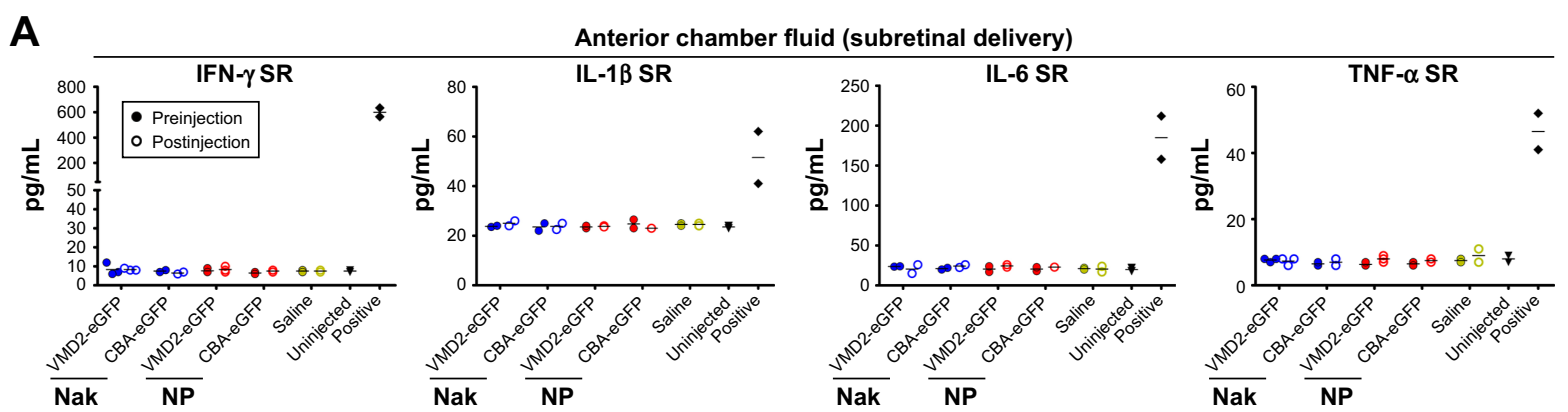

B

Anterior chamber fluid (intravitreal delivery)

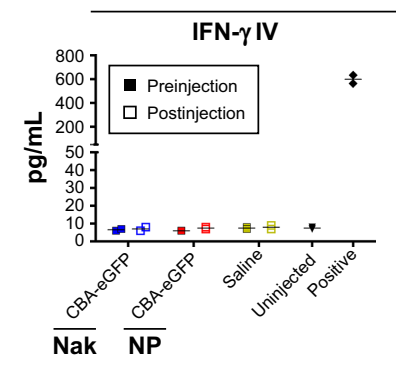

C
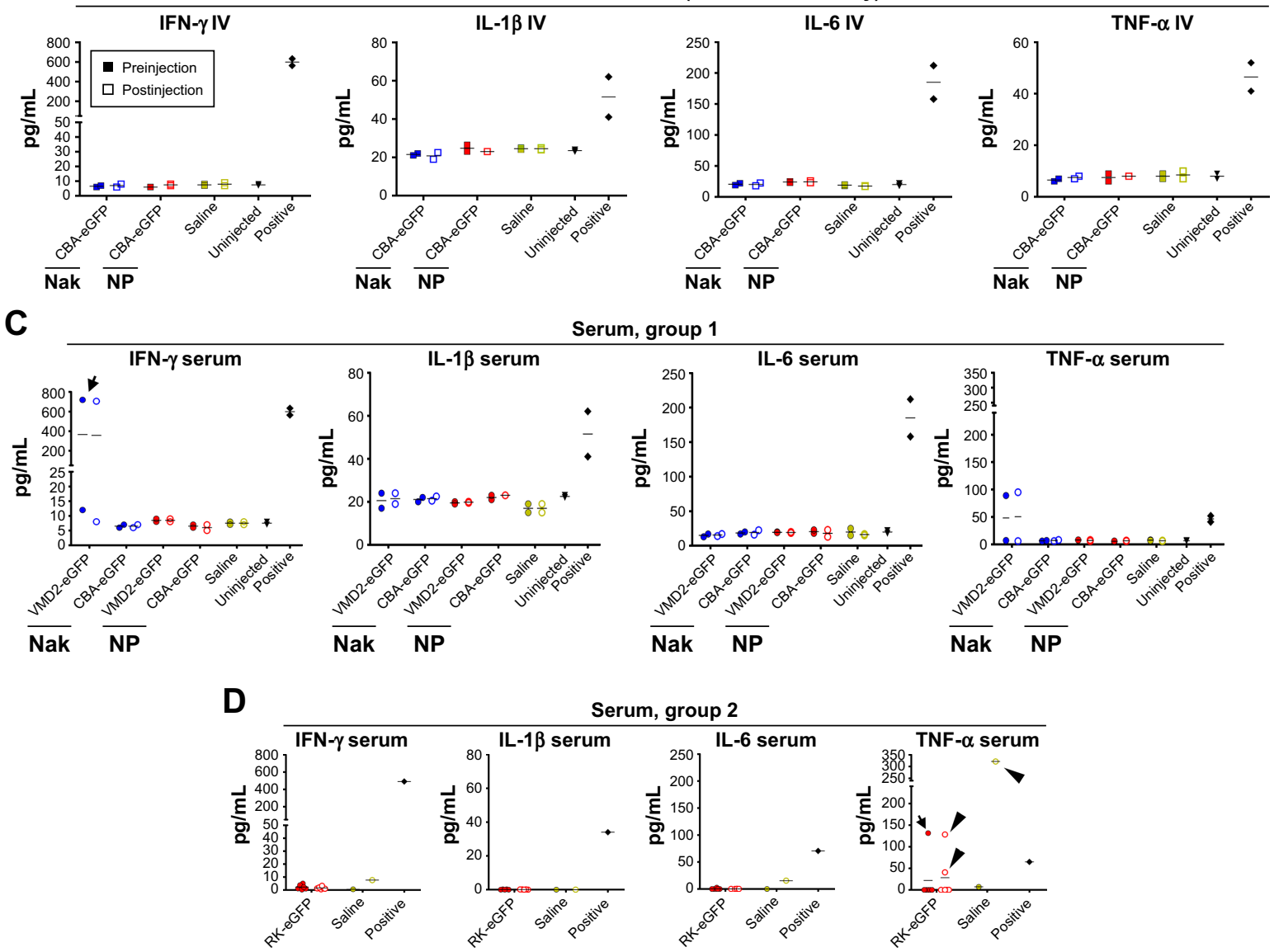

Serum, group 2

Figure 6 Inflammatory cytokines are not upregulated by NP injection in the baboon eye.

Notes: Aqueous humor and serum were collected before the injections (baseline, filled symbols) and at the endpoint (postinjection, open symbols; time as indicated in Table I). Samples were assayed for levels of IL-6, IFN- $\gamma$, IL-I $\beta$, or TNF- $\alpha$ protein using a non-human primate cytokine magnetic bead panel kit. Each eye is shown as an individual symbol with NPs in red, naked DNA in blue, saline in green, uninjected/positive control in black, and subretinal/intravitreal injection in circles/squares, respectively. Serum from a dengue fever virus-infected baboon was used as a positive control (diamond) and an uninjected animal was used as a negative control (triangle). (A) Graphical representation of data obtained from the aqueous humor of animals that received subretinal injections. (B) Graphical representation of data obtained from the aqueous humor of animals that received intravitreal injections. (C, D) Graphical representation of data obtained from the serum of animals that received subretinal injections in groups I and 2, respectively.

Abbreviations: IFN, interferon; IL, interleukin; IV, intravitreal injection; Nak, naked plasmid; NP, nanoparticle; SR, subretinal injection; TNF, tumor necrosis factor.

subretinal (Figure 6A) or intravitreal (Figure 6B) delivery. In addition, there was no difference between animals followed up at PI-15 vs PI-30 days. Significant expression of all the examined cytokines was detected in the positive control (confirming that the assay was working). This lack of cytokine response is consistent with the clinical finding that no animals exhibited any clinical sign of persistent inflammatory response after the injection.

To determine whether there was any injection or NPassociated inflammatory reaction outside the eye, the experiment was repeated using serum samples collected immediately before injection and at the study endpoint from 
eGFP DNA, Brain

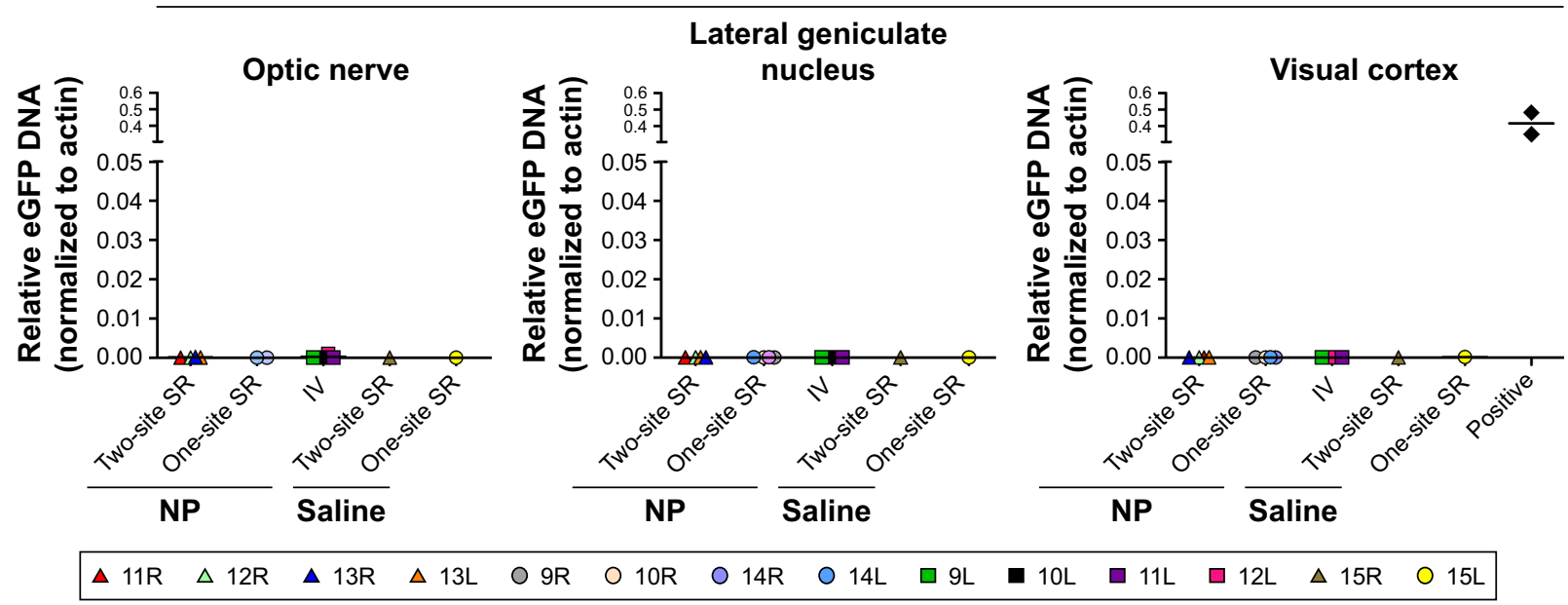

Figure 7 No RK-GFP DNA is detected in the brain.

Notes: The optic nerve, lateral geniculate nucleus, and visual cortex were harvested from animals subretinally (two-site or one-site) or intravitreally injected with NP RKGFP or saline at PI-45 days. Relative levels of GFP DNA were assessed by qPCR. Colors correspond to individual eyes; legend lists animal \#/eye. The positive control is optic nerve DNA spiked with naked RK-GFP (black diamond).

Abbreviations: IV, intravitreal injection; NP, nanoparticle; PI, postinjection; qPCR, quantitative polymerase chain reaction; RPE, retinal pigment epithelium; SR, subretinal injection.

group 1 animals (Figure 6C). There were no signs of treatment-associated cytokine elevation in the serum (Figure 6C). One baboon exhibited elevated serum IFN- $\gamma$ and TNF- $\alpha$ (Figure 6C, arrows, \#8) levels, but there was no change from baseline to the study endpoint and no elevation in the eye, so this increase is likely due to a pre-existing condition. We also repeated the cytokine analysis on serum collected from group 2 baboons (Figure 6D). Group 2 animals had no treatment-associated elevation in IL-6, IFN- $\gamma$, or IL- $1 \beta$ in serum. Three group 2 animals had elevated TNF- $\alpha$ between baseline and PI samples (Figure 6D, arrowheads, \#10, \#13, and \#15), including the saline-injected animal, while one animal (Figure 6D, arrow, \#11) had elevated TNF- $\alpha$ preinjection, which returned to undetectable levels by the end of the study. This mild inflammatory response is not likely to be due to the NPs since it occurs in the saline-treated animal as well as in 2 out of 12 NP-treated animals, and overall, there were no signs of a widespread systemic inflammatory response. These data combined indicate that the NPs are largely well tolerated after both subretinal and intravitreal injection.

Previously, we had observed that subretinally delivered AAV can reach the brain, while compacted DNA NPs do not. ${ }^{19}$ To determine whether NP-delivered DNA reaches the brain in the baboon eye, we isolated DNA from the optic nerve, lateral geniculate nucleus, and visual cortex from group 2 animals. No RK-GFP NP DNA was found in any of these tissues in any case (Figure 7). Taken together, these data suggest that NPs are not taken into the brain after ocular delivery, although a longer time course might be needed to rule out this possibility completely.

\section{Discussion}

Here we show effective ocular gene transfer without significant inflammatory response or NP-associated decreases in visual function in the baboon eye after delivery of CK30PEGcompacted DNA NPs. This is a critical advancement in the progression of this technology toward clinical testing. Consistent with our previous studies, ${ }^{2}$ gene expression was detected in the retina with NPs, and in the RPE with both NPs and naked DNA; however, levels varied widely from vector to vector, especially with naked DNA. For example, naked CBA-GFP resulted in almost no gene expression, while VMD2-GFP exhibited fairly good transfection with naked DNA. These results suggest that the vector content can significantly affect ocular gene transfer efficacy, an outcome we have previously observed. ${ }^{2,3}$

We assessed subretinal and intravitreal delivery, and one of the most exciting outcomes is that we observed reporter gene expression in the retina plus PECS, both on the message and protein levels, after intravitreal injection of NP-CBA-GFP. Although subretinal injection yielded better gene expression, the expression after intravitreal delivery is highly desirable given the invasive nature of subretinal delivery. Of note, studies in mice comparing subretinal to dose-escalated intravitreal delivery of a compacted VMD2luciferase as a reporter showed dose equivalence with a 
3-fold increase of the intravitreal dose (MJC, personal communication, 2017), which is comparable to the results obtained in baboons (Figure 1). It is also apparent that the inner limiting membrane of the baboon retina does not limit deep retinal diffusion of RK-GFP NPs (Figure 3B) as measured by qPCR. This finding is of substantial importance, since intravitreal dosing of AAV vectors substantially limits RPE gene transfer. ${ }^{23}$ Current retina/RPE-targeted gene therapies are being delivered subretinally; ${ }^{24,25}$ however, this procedure is invasive, and long-term sequelae as a result of the injection procedure are thought to impair the efficacy of the treatment. ${ }^{24}$ Consistent with this, our data here show that ERG outcomes were worse in the two-site subretinal group compared to the one-site subretinal group or the intravitreal group. Thus, development of effective intravitreal gene therapies is a high priority. However, although we saw good GFP expression (on the message and protein levels) in retina+PECS samples after intravitreal delivery of CBA-GFP NPs, we did not observe any GFP expression in the retina after intravitreal delivery of RK-GFP. Interestingly, we did observe NP DNA in the RPE after intravitreal delivery of RK-GFP. Overall, these observations lead us to hypothesize that the GFP expression we observed after subretinal/intravitreal injection in CBA-GFP eyes was in the RPE rather than photoreceptors. Furthermore, this suggests that intravitreally delivered material can reach the subretinal space, even if it is not efficiently taken up/expressed by photoreceptors, a phenomenon that has been seen previously with various other types of NPs. ${ }^{26,27}$ Given this observation, and the importance of intravitreal delivery, our future studies will likely focus on optimizing this approach along with enhancing photoreceptor uptake.

The role of the RPE in potentially affecting photoreceptor uptake is an important factor to consider. Here we find that after a single subretinal injection of NP-RK-GFP, gene expression and retinal NP-RK-GFP DNA are largely restricted to the region of injection. However, NP-RK-GFP DNA is detected in the RPE in all four quadrants, suggesting that the injected material is disseminated outside the region of injection, but that it is taken up by the RPE before having a chance to be internalized by photoreceptors. This is consistent with our previous observation that the RPE is easily transfected by both NPs and naked DNA after subretinal delivery, while photoreceptors are harder to transfect., ${ }^{2,920,28}$ The apparent preference for the RPE may be due to the wellestablished phagocytic nature of that tissue which easily takes up both endogenous material such as photoreceptor photoreceptor outer segments as well as exogenous material delivered to the subretinal space, ${ }^{29,30}$ and indeed, we have found that the RPE preferentially takes up NP DNA compared to photoreceptors. ${ }^{28}$ We know that NPs are internalized into airway epithelial cells by raft-associated nucleolinmediated endocytosis, ${ }^{31}$ and though we hypothesize that this process could occur in ocular cells, the mechanisms of NP uptake into and clearance from the RPE and retina have not been well studied. ${ }^{32}$ If, indeed, the low retina expression after delivery of RK-GFP is due to differential particle uptake by RPE cells vs photoreceptors, and photoreceptor transfection is the ultimate goal, there are several practical approaches that could potentially compensate for this difference. These could include delivery of more DNA to the subretinal or intravitreal space, timing delivery to coincide with the periods of the day at which RPE phagocytosis is lowest, and/or co-delivery of a drug that would increase retinal reattachment, such as the P2Y2 receptor agonist INS37217. ${ }^{33}$ In addition, judicious vector/NP engineering could minimize uptake in unwanted cells by the use of cell-type specific genes or the inclusion of receptor-targeting sequences on the NP.

A critical feature of our results is the lack of significant toxicity or side effects after delivery of the NPs. The animals exhibited no gross changes in vision-dependent behaviors or gross ocular pathologies and we did not observe any injection- or NP-associated degeneration in the retina. Twosite subretinal delivery of the NP-RK-GFP vector did result in a marked decrease in retinal function as measured by ERG, without any significant improvement in gene expression; so, this method may need to be refined or avoided in the future. One issue that can be a concern with genetic therapies is expression outside the tissue of interest. Although the eye is relatively separate from the systemic circulation (and thus, intraocular delivery rarely results in extraocular distribution), there have been some instances where treatments delivered to the eye are ectopically expressed in the brain. ${ }^{19,34-36}$ Importantly, we did not observe any signs of accumulation of NP DNA in the brain after intraocular delivery in the baboon. Finally, consistent with the apparently well-tolerated nature of the particles within the baboon eye, and lack of distribution outside it, we observe no signs of intraocular inflammation. Although we did observe elevation of serum TNF- $\alpha$ in 3 out of 15 animals, this occurred in vehicle as well as NPinjected animals. In addition, none of the other cytokines were elevated in these animals and there was no elevation in any serum cytokines evaluated in the remaining 12 animals. The absence of toxicity and low potential for insertional mutagenesis make compacted DNA NPs an exciting tool for gene delivery into the eye. 


\section{Conclusion}

Herein we show that CK30PEG DNA NPs carrying GFP reporter plasmids under the control of various promoters can safely drive gene expression in the baboon retina/RPE without generating substantial immune responses, although retinal transfection is limited. These particles are comparable to those we have previously used to provide phenotypic rescue in several rodent models of retinal disease. In the future, we will focus on assessing the long-term gene expression and optimizing the levels and distribution of expression in the non-human primate. Our findings, in combination with the well-established rodent safety and efficacy profiles of these DNA NPs strengthen this approach as a potentially clinically viable nonviral ocular therapy platform for retinal diseases.

\section{Acknowledgments}

The authors thank Dr Roman F Wolf and David W Carey at the Division of Comparative Medicine at Oklahoma Health Sciences Center for their help in handling and caring for the baboons used in this study. They also thank Dr Rahel Zulliger, Dr Michael Stuck, and Dr Adarsha Koirala for technical assistance. This work was supported by the National Eye Institute (EY08656-MIN and EY22778-MIN).

Current address for RAK: Skaggs School of Pharmacy and Pharmaceutical Sciences, University of Colorado, Anschutz Medical Center, Aurora, CO, USA. Current address for ZH: Department of Ophthalmology, University of North Carolina, Chapel Hill, NC, USA.

\section{Author contributions}

Conceptualization: MIN; methodology: MIN, SMC, RAK, ZH; validation: RAK, SMC, MIN; formal analysis: RAK, SMC; investigation: RAK, SMC, RM, JNW, ZH, MIN; resources: MIN, MJC; writing-original draft: RAK, SMC, ZH; writing, reviewing, and editing: $\mathrm{SMC}, \mathrm{RAK}, \mathrm{MIN}, \mathrm{MJC}, \mathrm{ZH}$; supervision, project administration, funding acquisition: MIN. All authors contributed toward data analysis, drafting and revising the paper and agree to be accountable for all aspects of the work.

\section{Disclosure}

MJC is an employee of Copernicus Therapeutics and owns stock in the company. The authors report no other conflicts of interest in this work.

\section{References}

1. Koirala A, Conley SM, Makkia R, et al. Persistence of non-viral vector mediated RPE65 expression: case for viability as a gene transfer therapy for RPE-based diseases. J Control Release. 2013;172(3):745-752.
2. Koirala A, Makkia RS, Conley SM, Cooper MJ, Naash MI. S/MARcontaining DNA nanoparticles promote persistent RPE gene expression and improvement in RPE65-associated LCA. Hum Mol Genet. 2013; 22(8): 1632-1642.

3. Cai X, Nash Z, Conley SM, Fliesler SJ, Cooper MJ, Naash MI. A partial structural and functional rescue of a retinitis pigmentosa model with compacted DNA nanoparticles. PLoS One. 2009;4(4):e5290.

4. Farjo R, Skaggs J, Quiambao AB, Cooper MJ, Naash MI. Efficient non-viral ocular gene transfer with compacted DNA nanoparticles. PLoS One. 2006; 1:e38.

5. Han Z, Koirala A, Makkia R, Cooper MJ, Naash MI. Direct gene transfer with compacted DNA nanoparticles in retinal pigment epithelial cells: expression, repeat delivery and lack of toxicity. Nanomedicine (Lond). 2012;7(4):521-539.

6. Cai X, Conley SM, Nash Z, Fliesler SJ, Cooper MJ, Naash MI. Gene delivery to mitotic and postmitotic photoreceptors via compacted DNA nanoparticles results in improved phenotype in a mouse model of retinitis pigmentosa. FASEB J. 2010;24(4):1178-1191.

7. Zheng M, Mitra RN, Filonov NA, Han Z. Nanoparticle-mediated rhodopsin cDNA but not intron-containing DNA delivery causes transgene silencing in a rhodopsin knockout model. FASEB J. 2016; 30(3):1076-1086.

8. Han Z, Banworth MJ, Makkia R, et al. Genomic DNA nanoparticles rescue rhodopsin-associated retinitis pigmentosa phenotype. FASEB J. 2015;29(6):2535-2544.

9. Han Z, Conley SM, Makkia RS, Cooper MJ, Naash MI. DNA nanoparticle-mediated ABCA4 delivery rescues Stargardt dystrophy in mice. J Clin Invest. 2012;122(9):3221-3226.

10. Padegimas L, Kowalczyk TH, Adams S, et al. Optimization of hCFTR lung expression in mice using DNA nanoparticles. Mol Ther. 2012; 20(1):63-72.

11. Yurek DM, Flectcher AM, Kowalczyk TH, Padegimas L, Cooper MJ. Compacted DNA nanoparticle gene transfer of GDNF to the rat striatum enhances the survival of grafted fetal dopamine neurons. Cell Transplant. 2009;18(10):1183-1196.

12. Yurek DM, Fletcher AM, McShane M, et al. DNA nanoparticles: detection of long-term transgene activity in brain using bioluminescence imaging. Mol Imaging. 2011;10(5):327-339.

13. Ziady AG, Gedeon CR, Miller T, et al. Transfection of airway epithelium by stable PEGylated poly-L-lysine DNA nanoparticles in vivo. Mol Ther. 2003;8(6):936-947.

14. Ziady AG, Gedeon CR, Muhammad O, et al. Minimal toxicity of stabilized compacted DNA nanoparticles in the murine lung. Mol Ther. 2003;8(6):948-956.

15. Ding XQ, Quiambao AB, Fitzgerald JB, Cooper MJ, Conley SM, Naash MI. Ocular delivery of compacted DNA-nanoparticles does not elicit toxicity in the mouse retina. PLoS One. 2009;4(10):e7410.

16. Fink TL, Klepcyk PJ, Oette SM, et al. Plasmid size up to $20 \mathrm{kbp}$ does not limit effective in vivo lung gene transfer using compacted DNA nanoparticles. Gene Ther. 2006;13(13):1048-1051.

17. Murthy KK, Salas MT, Carey KD, Patterson JL. Baboon as a nonhuman primate model for vaccine studies. Vaccine. 2006;24(21):4622-4624.

18. McFarlane D, Wolf RF, McDaniel KA, White GL. Age-associated alteration in innate immune response in captive baboons. $J$ Gerontol A Biol Sci Med Sci. 2011;66(12):1309-1317.

19. Han Z, Conley SM, Makkia R, Guo J, Cooper MJ, Naash MI. Comparative analysis of DNA nanoparticles and AAVs for ocular gene delivery. PLoS One. 2012;7(12):e52189.

20. Koirala A, Makkia RS, Cooper MJ, Naash MI. Nanoparticle-mediated gene transfer specific to retinal pigment epithelial cells. Biomaterials. 2011;32(35):9483-9493.

21. Liu G, Li D, Pasumarthy MK, et al. Nanoparticles of compacted DNA transfect postmitotic cells. J Biol Chem. 2003;278(35):32578-32586.

22. Rhee JM, Pirity MK, Lackan CS, et al. In vivo imaging and differential localization of lipid-modified GFP-variant fusions in embryonic stem cells and mice. Genesis. 2006;44(4):202-218. 
23. Dalkara D, Kolstad KD, Caporale N, et al. Inner limiting membrane barriers to AAV-mediated retinal transduction from the vitreous. $\mathrm{Mol}$ Ther. 2009;17(12):2096-2102.

24. Jacobson SG, Cideciyan AV, Ratnakaram R, et al. Gene therapy for leber congenital amaurosis caused by RPE65 mutations: safety and efficacy in 15 children and adults followed up to 3 years. Arch Ophthalmol. 2012;130(1):9-24.

25. Maguire AM, Simonelli F, Pierce EA, et al. Safety and efficacy of gene transfer for Leber's congenital amaurosis. $N$ Engl J Med. 2008; 358(21):2240-2248.

26. Kim H, Robinson SB, Csaky KG. Investigating the movement of intravitreal human serum albumin nanoparticles in the vitreous and retina. Pharm Res. 2009;26(2):329-337.

27. Koo H, Moon H, Han H, et al. The movement of self-assembled amphiphilic polymeric nanoparticles in the vitreous and retina after intravitreal injection. Biomaterials. 2012;33(12):3485-3493.

28. Koirala A, Conley SM, Naash MI. Episomal maintenance of S/MARcontaining non-viral vectors for RPE-based diseases. Adv Exp Med Biol. 2014;801:703-709.

29. de Queiroz JM Jr, Blanks JC, Ozler SA, Alfaro DV, Liggett PE. Subretinal perfluorocarbon liquids. An experimental study. Retina. 1992; 12(3 Suppl):S33-S39.
30. Kevany BM, Palczewski K. Phagocytosis of retinal rod and cone photoreceptors. Physiology (Bethesda). 2010;25(1):8-15.

31. Chen X, Shank S, Davis PB, Ziady AG. Nucleolin-mediated cellular trafficking of DNA nanoparticle is lipid raft and microtubule dependent and can be modulated by glucocorticoid. Mol Ther. 2011;19(1): 93-102.

32. Conley SM, Naash MI. Nanoparticles for retinal gene therapy. Prog Retin Eye Res. 2010;29(5):376-397.

33. Farjo R, Peterson WM, Naash MI. Expression profiling after retinal detachment and reattachment: a possible role for aquaporin-0. Invest Ophthalmol Vis Sci. 2008;49(2):511-521.

34. Dudus L, Anand V, Acland GM, et al. Persistent transgene product in retina, optic nerve and brain after intraocular injection of rAAV. Vision Res. 1999;39(15):2545-2553.

35. Guy J, Qi X, Muzyczka N, Hauswirth WW. Reporter expression persists 1 year after adeno-associated virus-mediated gene transfer to the optic nerve. Arch Ophthalmol. 1999;117(7):929-937.

36. Provost N, Le Meur G, Weber M, et al. Biodistribution of rAAV vectors following intraocular administration: evidence for the presence and persistence of vector DNA in the optic nerve and in the brain. Mol Ther. 2005;11(2):275-283. 


\section{Supplementary materials}

A

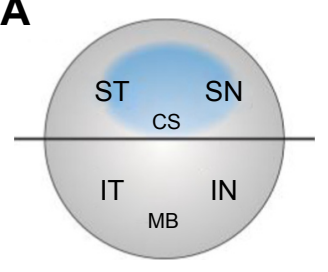

$2 R, 3 R, 4 R$

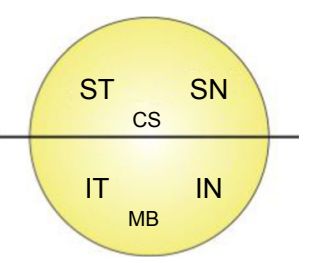

$2 \mathrm{~L}, 3 \mathrm{~L}, 4 \mathrm{~L}$
B

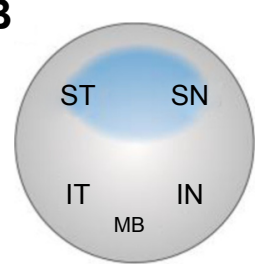

$5 \mathrm{R}, 5 \mathrm{~L}$

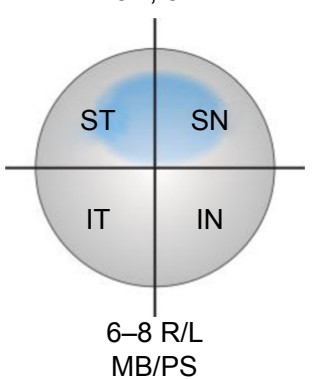

C

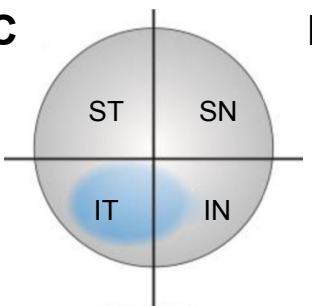

$9 \mathrm{R}, 15 \mathrm{~L}$

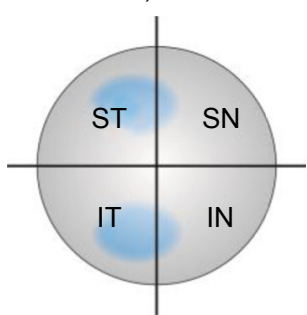

11R, 13L, 13R

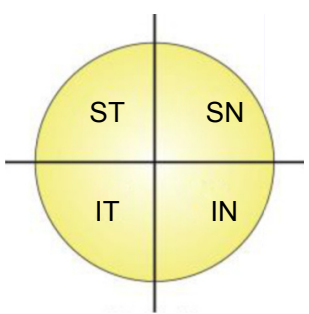

9L, 11L

MB

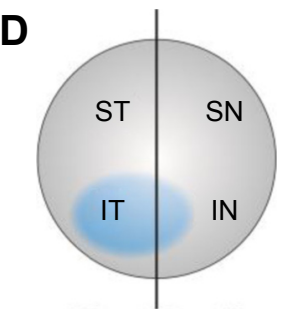

10R, 14R, 14L

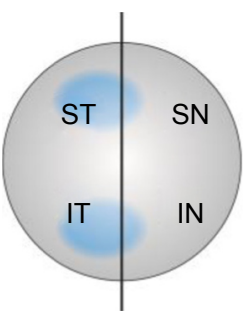

$12 \mathrm{R}, 15 \mathrm{R}$

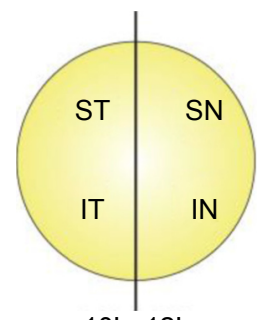

10L, 12L

PS

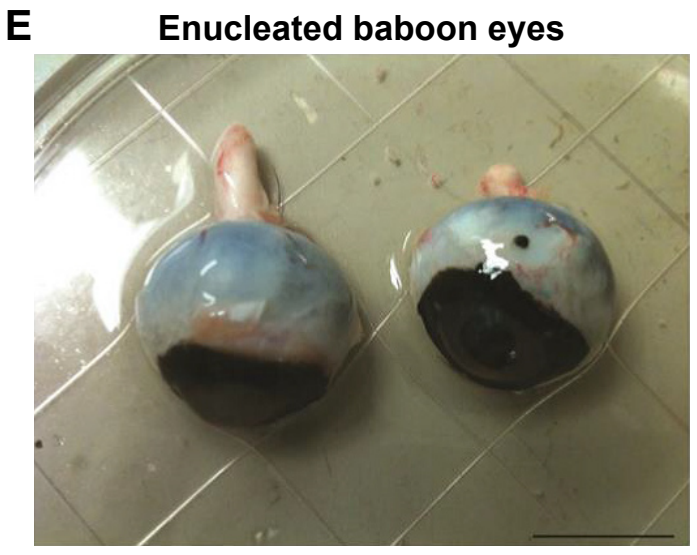

Figure SI Diagram of injection and collection paradigms for subretinally injected eyes.

Notes: Blue in each diagram represents approximate region of subretinally injected eyes. Intravitreally injected eyes are colored yellow to indicate presumptive diffusion of material throughout the vitreous. Lines indicate approximately how eyes were dissected. Numbers below illustrations correspond with individual animals enrolled in this study. (A) Eyes injected with saline or CBA-GFP. (B) Eyes injected with VMD2-GFP (divided into quadrants except for 5L and 5R which were collected as bulk tissue). (C) Eyes injected with RK-GFP and processed for molecular biology (divided into quadrants). (D) Eyes injected with RK-GFP and processed for sectioning along the inferiorsuperior plane as indicated by the line. (E) Photograph of enucleated baboon eyes; scale bar is $2 \mathrm{~cm}$.

Abbreviations: CS, tissue collected for cryosectioning; IN, inferior nasal; IT, inferior temporal; MB, tissue collected for molecular biology/protein chemistry; PS, tissue collected for paraffin sectioning; SN, superior nasal; ST, superior temporal. 
Table SI Eye measurements for comparison of baboon eye with human and mouse

\begin{tabular}{|c|c|c|c|c|}
\hline Ocular Parameters & Human & Baboon & $\begin{array}{l}\text { Monkey (cynomolgus } \\
\text { monkey) }\end{array}$ & Mouse \\
\hline Axial length, mm & $23.2^{\prime}$ & $2 l^{\mathrm{a}}$ & $18.9^{1}$ & $3.37^{2}$ \\
\hline Corneal thickness, mm & $0.52^{\prime}$ & $\sim 0.46^{\mathrm{b}}$ & $0.4^{3}$ & \\
\hline Anterior chamber depth, mm & $3.28^{\prime}$ & $\sim 3.26^{\mathrm{b}}$ & $3.24^{3}$ & \\
\hline Lens thickness, $\mathrm{mm}$ & $3.89^{1}$ & $\sim 3.4^{b}$ & $2.98^{3}$ & \\
\hline \multirow[t]{2}{*}{ Vitreous chamber depth, mm } & 14.891 & $\sim 12.9^{b}$ & $10.9^{1}$ & \\
\hline & & $\sim 12.8^{c}$ & & \\
\hline Combined retinal, scleral, choroidal thickness, mm & $1.14^{\prime}$ & $\sim 1.07^{\mathrm{b}}$ & $1.0^{1}$ & \\
\hline Vitreous volume, $\mu \mathrm{L}$ & $4,700^{\prime}$ & $\sim 3,400^{\mathrm{b}}$ & $2,100^{1}$ & $5.3^{2}$ \\
\hline SA of subretinal space, $\mathrm{mm}^{2}$ & $1,024^{4}$ & $\sim 839^{d}$ & & $15.6^{2}$ \\
\hline Nanoparticles delivered vol in $\mu \mathrm{L} @$ DNA conc $\mu \mathrm{g} / \mu \mathrm{L}$ & & $100-150 @ 4.3 \mu \mathrm{g} / \mu \mathrm{L}$ & & $1 @ 4.3^{5-7}$ \\
\hline Effective dose (intravitreal) $\mu \mathrm{g} \mathrm{NP} \mathrm{DNA} / \mu \mathrm{L}$ vitreous volume & & 0.12 & & 0.81 \\
\hline Effective dose (subretinal) $\mu \mathrm{g}$ NP DNA $/ \mathrm{mm}^{2}$ retinal SA & & 0.51 & & 0.27 \\
\hline
\end{tabular}

Notes: ${ }^{a}$ Refers to axial length measured from enucleated animals used in the current study. ${ }^{b}$ Refers to values estimated as the mean of the respective measurements in humans and monkeys. 'This value was estimated as measured axial length-corneal thickness-anterior chamber depth-lens thickness-retina/PECS thickness. ${ }^{\mathrm{d}}$ This value is calculated as (retina SA human/total ocular SA human) $\times$ (total ocular SA baboon).

Abbreviations: NP, nanoparticle; PECS, pigment epithelium/choroid/sclera; SA, surface area.

Table S2 History and characteristics of the baboons

\begin{tabular}{|c|c|c|c|}
\hline Animal \# & $\begin{array}{l}\text { Age } \\
\text { (years) }\end{array}$ & Sex & Prior study history \\
\hline \multicolumn{4}{|l|}{ Group I } \\
\hline \multicolumn{4}{|l|}{ Controls } \\
\hline I & 20 & M & No research history, breeder \\
\hline 2 & 22 & $\mathrm{~F}$ & No research history, breeder \\
\hline \multicolumn{4}{|l|}{ CBA-GFP } \\
\hline 3 & 15 & $\mathrm{~F}$ & No research history, breeder \\
\hline 4 & 15 & M & No research history, breeder \\
\hline \multicolumn{4}{|l|}{ VMD2-GFP } \\
\hline 5 & 22 & $\mathrm{~F}$ & No research history, breeder \\
\hline \multirow[t]{2}{*}{6} & 22 & $\mathrm{~F}$ & 1996: Vaccinated with hepatitis B vaccine \\
\hline & & & 2000: C-section \\
\hline \multirow[t]{2}{*}{7} & 20 & $\mathrm{~F}$ & 2000: C-section \\
\hline & & & 2005: HIV vaccine study \\
\hline 8 & 17 & $\mathrm{~F}$ & No research history, breeder \\
\hline \multicolumn{4}{|l|}{ Group 2} \\
\hline \multicolumn{4}{|l|}{ RK-GFP } \\
\hline \multirow[t]{3}{*}{9} & 6 & M & 20II: Xenotransplant study \\
\hline & & & 2012: Ehrlichia study: attempted to infect with Erlichia using ticks \\
\hline & & & 2013: Vaccinated with RSV vaccine to generate polyclonal antibodies \\
\hline \multirow[t]{3}{*}{10} & 6 & M & 20I I: Xenotransplant study \\
\hline & & & 20।2: Erlichia study; attempted to infect with Ehrlichia using ticks \\
\hline & & & 2013: Vaccinated with RSV vaccine to generate polyclonal antibodies \\
\hline \multirow[t]{3}{*}{11} & 6 & M & 20II: Xenotransplant study \\
\hline & & & 2012: Erlichia study; attempted to infect with Ehrlichia using ticks \\
\hline & & & $\begin{array}{l}\text { 2013: Vaccinated with respiratory syncytial virus vaccine to } \\
\text { generate polyclonal antibodies }\end{array}$ \\
\hline \multirow[t]{2}{*}{12} & 6 & M & 20II: Xenotransplant study \\
\hline & & & 2012: Erlichia study; attempted to infect with Ehrlichia using ticks \\
\hline \multirow[t]{3}{*}{13} & 12 & M & 2005: On study for the therapeutic efficacy of compound used to \\
\hline & & & increase fetal hemoglobin in red blood cells \\
\hline & & & Breeder \\
\hline 14 & 2 & M & No research history; has history of seizures \\
\hline \multicolumn{4}{|l|}{ Controls } \\
\hline 15 & 7 & M & No research history; has history of seizures \\
\hline
\end{tabular}

Note: The 15 baboons enrolled in this study are described, including previous research history. 


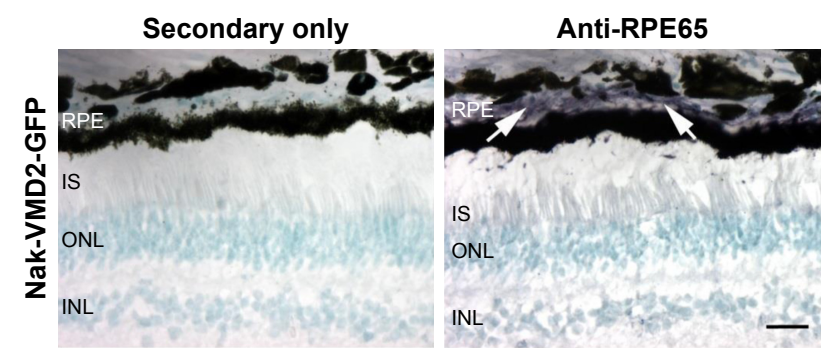

Figure S2 RPE65 expression in the baboon eye.

Notes: Sections from an eye injected with naked-VMD2-GFP were incubated with RPE65 antibody (right, purple) or secondary antibody alone (left). Nuclei are counterstained with methyl green (teal). Arrows indicate purple RPE65 labeling in the RPE. Images are from animal 7R. Images captured at $40 \times$, scale bar $25 \mu \mathrm{m}$.

Abbreviations: INL, inner nuclear layer; IS, inner segment; ONL, outer nuclear layer; RPE, retinal pigment epithelium.
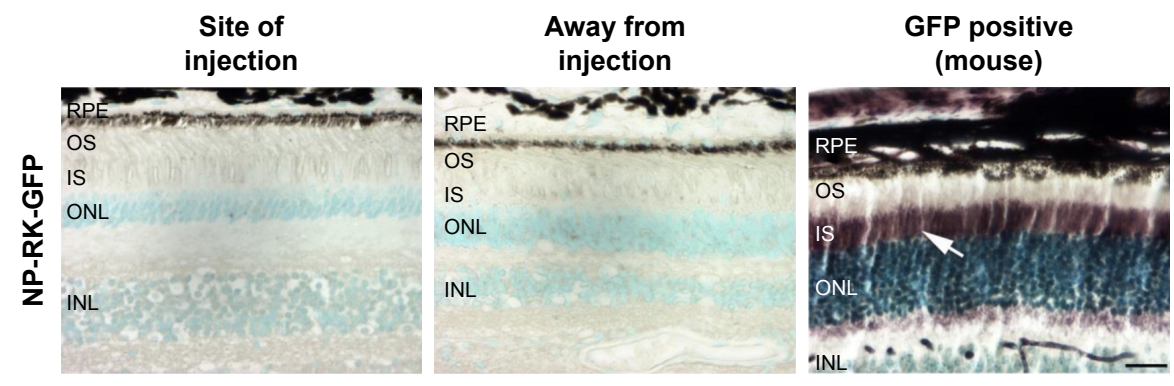

Figure S3 GFP protein is not detected in NP-RK-GFP SR-injected eyes.

Notes: Sections from an eye injected at one site with NP-RK-GFP (\#I4L) in the quadrant of injection (left) and away from the quadrant of injection (middle) were incubated with GFP antibody (purple) and counterstained with methyl green (teal). Sections from a transgenic mouse expressing GFP under a photoreceptor-specific promoter (retbindin) were used as a positive control (right). Arrow indicates GFP expression in the IS of photoreceptors from the positive control mouse. Images captured at $40 \times$. Images are from animal I4L. Scale bar $25 \mu \mathrm{m}$.

Abbreviations: SR, subretinal injection; INL, inner nuclear layer; IS, inner segment; ONL, outer nuclear layer; OS, outer segment; RPE, retinal pigment epithelium.

\section{References}

1. Missel PJ. Simulating intravitreal injections in anatomically accurate models for rabbit, monkey, and human eyes. Pharm Res. 2012;29: 3251-3272.

2. Jeon CJ, Strettoi E, Masland RH. The major cell populations of the mouse retina. J Neurosci. 1998;18:8936-8946.

3. Lapuerta P, Schein SJ. A four-surface schematic eye of macaque monkey obtained by an optical method. Vision Res. 1995;35:2245-2254.

4. Panda-Jonas S, Jonas JB, Jakobczyk M, et al. Retinal photoreceptor count, retinal surface area, and optic disc size in normal human eyes. Ophthalmology. 1994;101:519-523.
5. Cai X, Cooper M, Naash M. Effective gene transfer for leber congenital amaurosis with compacted Dna nanoparticle. Invest Ophthalmol Vis Sci. 2009;50:1737.

6. Han Z, Koirala A, Makkia R, et al. Direct gene transfer with compacted DNA nanoparticles in retinal pigment epithelial cells: expression, repeat delivery and lack of toxicity. Nanomedicine (Lond). 2012;7:521-539.

7. Farjo R, Skaggs J, Quiambao AB, et al. Efficient non-viral ocular gene transfer with compacted DNA nanoparticles. PLoS One. 2006;1:e38.
International Journal of Nanomedicine

\section{Publish your work in this journal}

The International Journal of Nanomedicine is an international, peerreviewed journal focusing on the application of nanotechnology in diagnostics, therapeutics, and drug delivery systems throughou the biomedical field. This journal is indexed on PubMed Central, MedLine, CAS, SciSearch ${ }^{\circledR}$, Current Contents ${ }^{\circledR} /$ Clinical Medicine,

\section{Dovepress}

Journal Citation Reports/Science Edition, EMBase, Scopus and the Elsevier Bibliographic databases. The manuscript management system is completely online and includes a very quick and fair peer-review system, which is all easy to use. Visit http://www.dovepress.com/ testimonials.php to read real quotes from published authors. 